\title{
PREFERENCE DRIVEN UNIVERSITY COURSE SCHEDULING SYSTEM
}

\author{
A Thesis \\ Presented to \\ the Faculty of California Polytechnic State University, \\ San Luis Obispo
}

\author{
In Partial Fulfillment \\ of the Requirements for the Degree \\ Master of Science in Industrial Engineering
}

by

Heather Bellardo

June 2010 
(C) 2010

Heather Bellardo

ALL RIGHTS RESERVED 


\section{COMMITTEE MEMBERSHIP}

TITLE:

Preference Driven University Course Scheduling System

AUTHOR: Heather Bellardo

DATE SUBMITTED: June 2010

COMMITTEE CHAIR: Tali Freed, Professor

COMMITTEE MEMBER: Sema Alptekin, Professor

COMMITTEE MEMBER: Lizabeth Schlemer, Professor 


\author{
ABSTRACT \\ Preference Driven University Course Scheduling System \\ Heather Bellardo
}

\begin{abstract}
University course planning and scheduling is the process of determining what courses to offer, how many sections are needed, determining the best term to offer each section, assigning a faculty member to instruct each section, and scheduling each section to a timeslot to avoid conflicts. The result of this task has an impact on every student and faculty member in the department. The process is typically broken down into three major phases: course offering planning, faculty assignment to planned course sections, and course scheduling into timeslots.

This thesis looks at each of these phases for the Industrial and Manufacturing department and brings them together into a decision support and scheduling system. A decision support tool is created to facilitate planning of course offerings. Operations research is applied to assign sections to faculty members using a faculty preference driven integer linear programming model in order to minimize dissatisfaction in the department. Next, the faculty-section pairs are scheduled into university timeslots using a complex integer linear programming model. This scheduling model takes into consideration the faculty member time availability and preferences and general student time slot preferences as it minimizes dissatisfaction while avoiding conflicts among labs, faculty members and courses offered for each class level.
\end{abstract}

Keywords: faculty course assignment, course scheduling, course timetable. 


\section{Table of Contents}

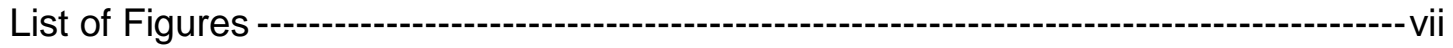

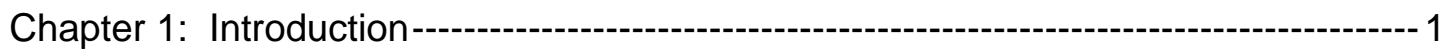

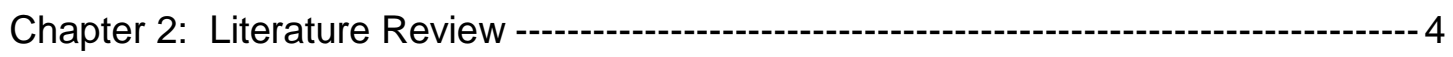

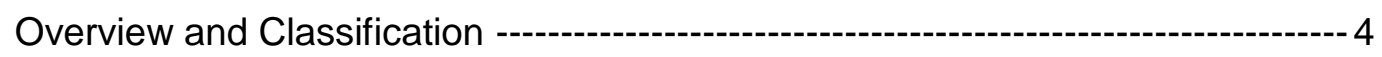

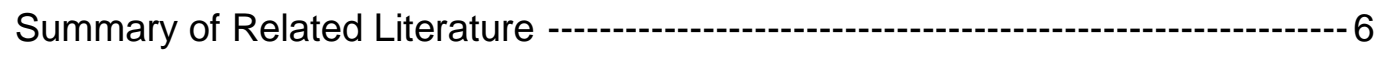

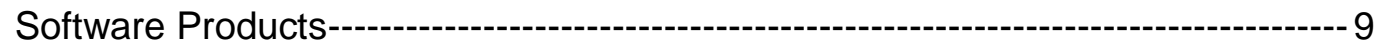

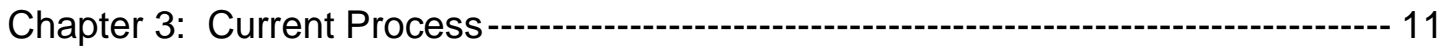

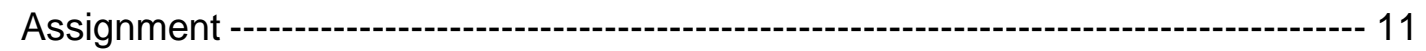

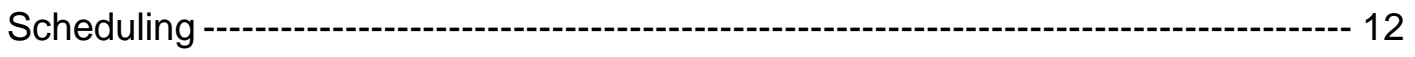

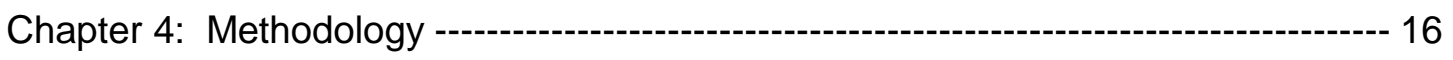

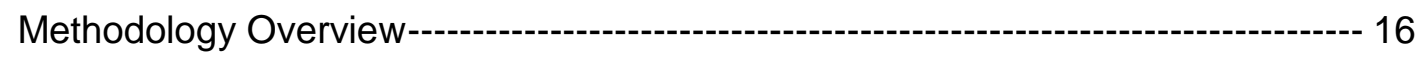

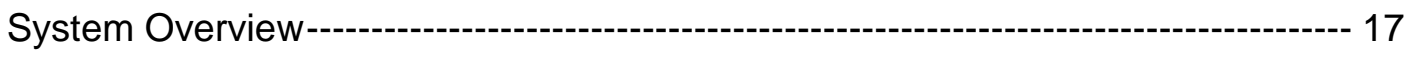

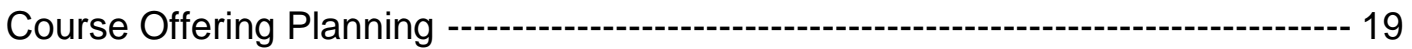

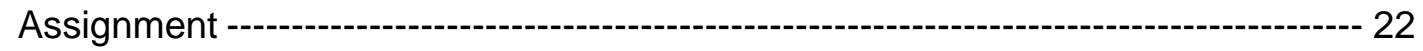

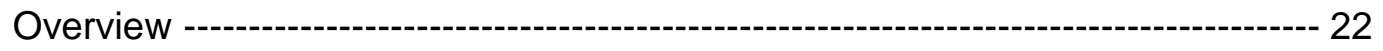

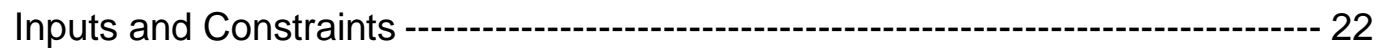

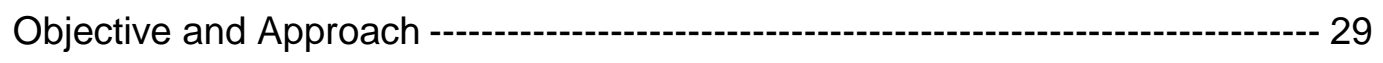

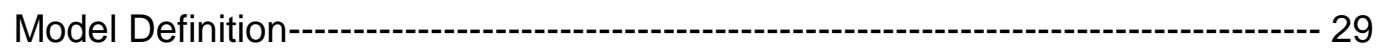

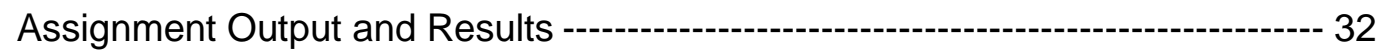

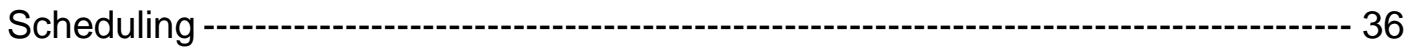


Overview

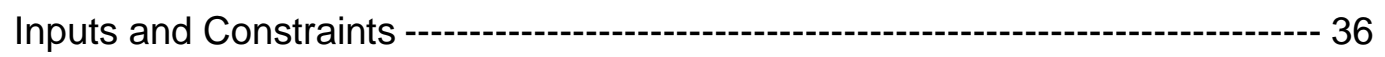

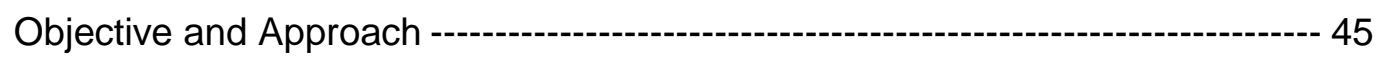

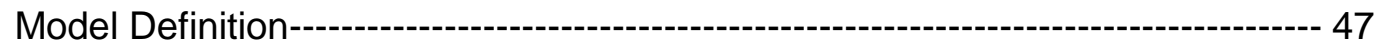

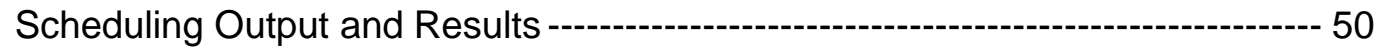

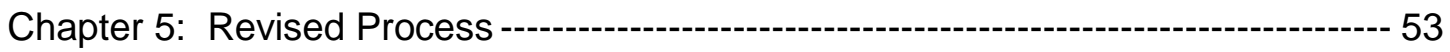

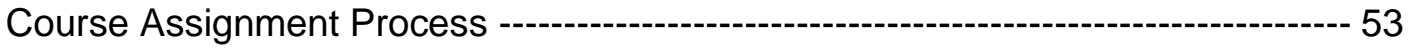

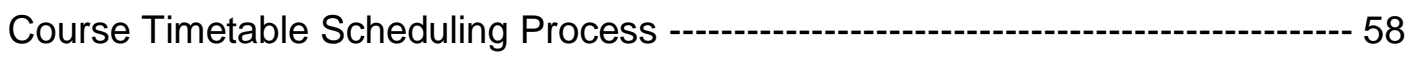

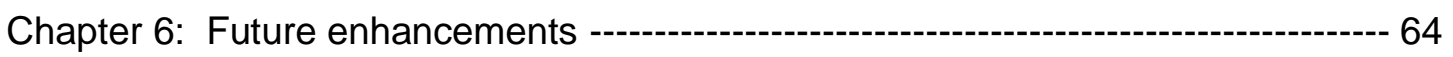

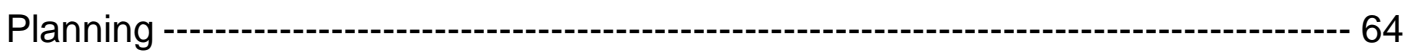

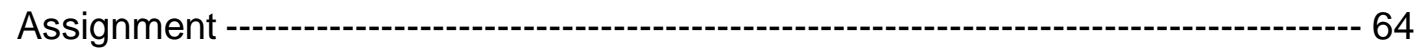

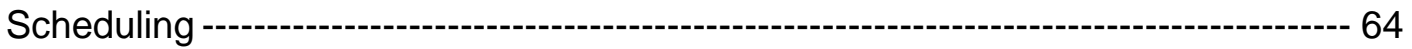

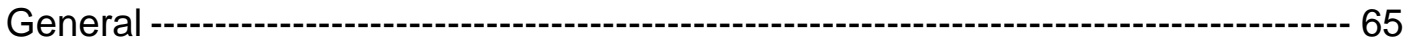

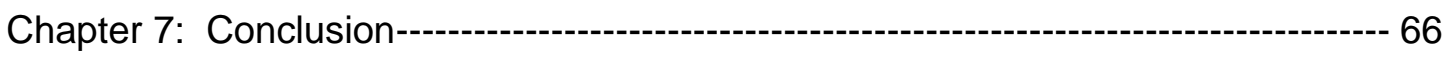

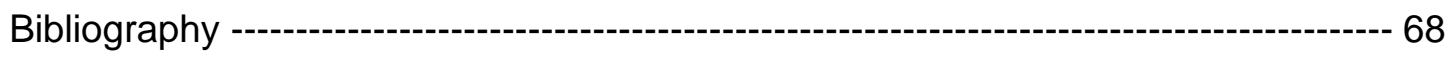

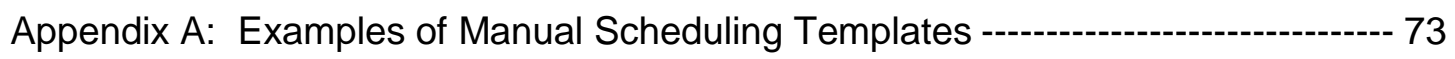




\section{List of Figures}

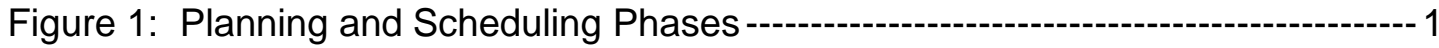

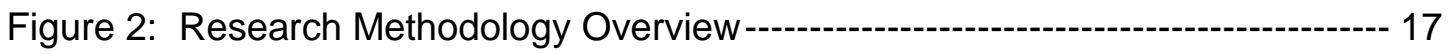

Figure 3: Planned Course Offering Inputs ---------------------------------------------------- 20

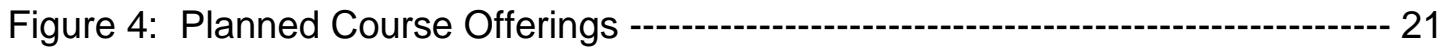

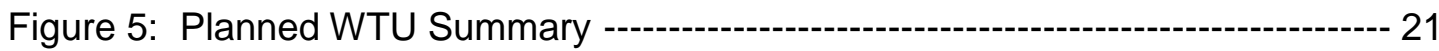

Figure 6: Faculty to Course Assignment Inputs ---

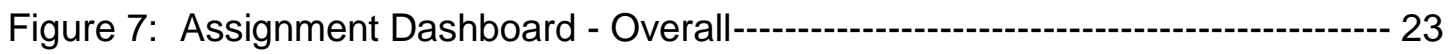

Figure 8: Assignment Dashboard - Faculty Workload Targets ------------------------- 25

Figure 9: Assignment Dashboard - Faculty Preferences---------------------------------- 27

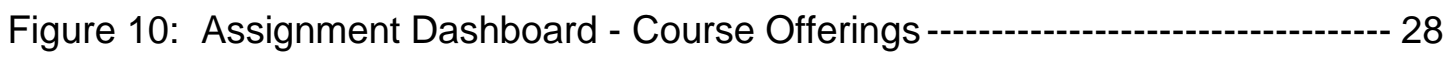

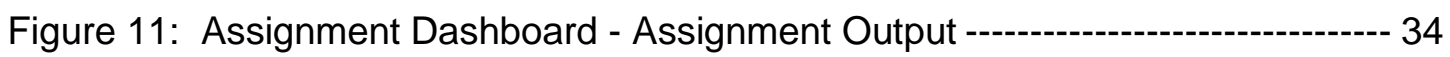

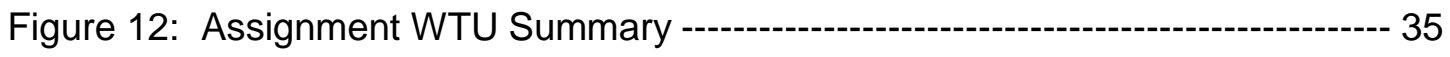

Figure 13: Assignment of Courses to Faculty Report------------------------------------- 35

Figure 14: Faculty Time Preference Key------------------------------------------------------- 37

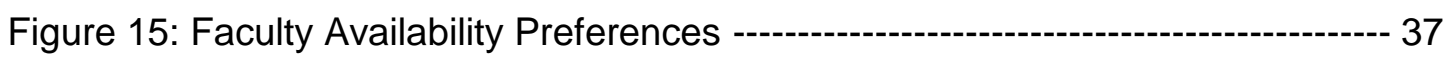

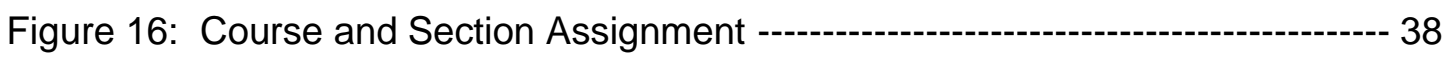

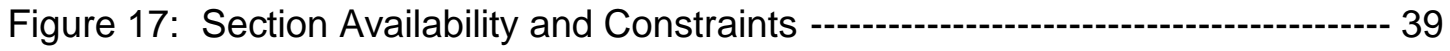

Figure 18: University Schedule Time Patterns ---------------------------------------------- 40

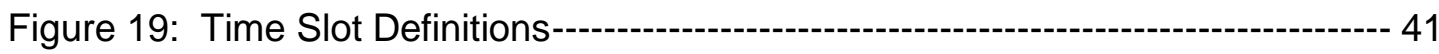

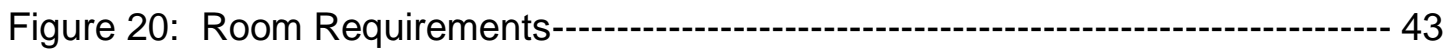

Figure 21: Course Conflict Constraints---------------------------------------------------------- 44

Figure 22: Scheduling Dashboard - Feasible Timeslots----------------------------------- 46

Figure 23: Scheduling Dashboard - Conflict Constraints --------------------------------- 47

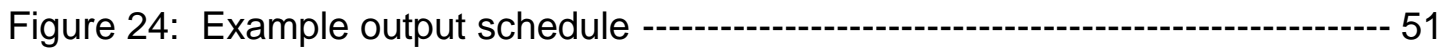




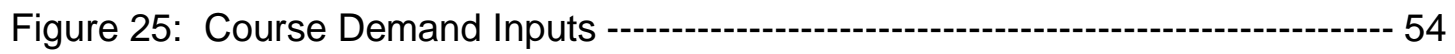

Figure 26: Target Teaching Load Calculation ---------------------------------------------- 55

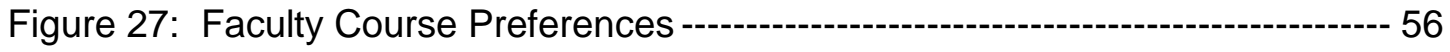

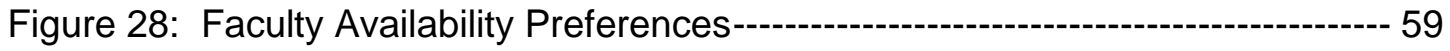

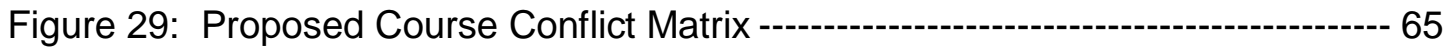

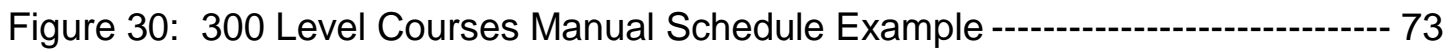

Figure 31: 400 Level Courses Manual Schedule Example -------------------------- 74

Figure 32: 500 Level Courses Manual Schedule Example ------------------------------ 75

Figure 33: Lab Room 192-221 Manual Schedule Example ------------------------------ 76

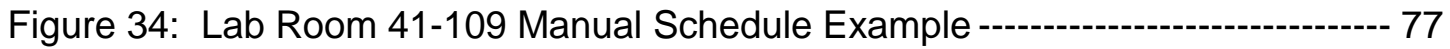

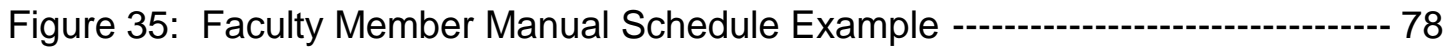




\section{Chapter 1: Introduction}

University course planning and scheduling is the process of determining what courses to offer, how many sections are needed, determining the best term to offer each section, assigning a faculty member to instruct each section, and scheduling each section to a timeslot to avoid conflicts. This process is typically broken down into three major phases: planning, faculty assignment, and course scheduling.

\section{Planning and Scheduling}

\section{Planning Course Offerings \\ Scheduling Sections into the Timetable}

Figure 1: Planning and Scheduling Phases

This process is a very large, complex, and time consuming task with many inputs to take into consideration. The quality of the output has a immense impact on students, faculty, and the department as a whole. Poorly planned offerings can impact students' ability to take courses, class utilization, students' ability to fulfill prerequisites, time to graduation, budget, and more. Poorly assigned faculty can impact the quality of instruction, the satisfaction of faculty members, student retention, and department politics. Poorly scheduled timetable can affect students' ability to take courses due to conflict, course utilization, lab utilization, time to graduation, student satisfaction, faculty satisfaction, department politics, and it can lead to undesirable last minute changes. This process partially defines the lives of students and faculty members in terms of schedule and should not be taken lightly. Because of the impact of this process it is 
important to incorporate individual and group preference into as many areas of this process as possible and to create a robust process that generates close to optimal solutions.

There has been research around course assignment and course timetabling and many operations research techniques have been utilized to address these problems, however often the techniques are tested, but rarely implemented as shown by Carter and Lamporte (1998). While some solutions have been fully implemented and there are a couple products available in the market, those weren't thoroughly investigated due to the software and implementation cost associated with them. Since much of the research focuses only on generating a feasible schedule and appears to lack the preference drivers that are valuable in creating a highly desirable schedule I felt there was room for further research in this area. We have taken into consideration 3 types of preferences in this research: faculty preference to teach a course, faculty preference for teaching time of day, and student/general department preference for each timeslot. Additionally, this approach is unique because it takes a systems approach by looking at the entire process instead of just one piece of the puzzle.

The focus of this case study is the Cal Poly Industrial and Manufacturing Engineering department. The current process is a purely manual process that incorporates some preferences for assignment and attempts to avoid conflicts for scheduling. Due to the complexity of the problem, this manual process is prone to error and is extremely time consuming. With a manual approach as the base line, there is a great deal of room for improvement.

In the following chapters, I have summarized existing work in the field of faculty assignment and course scheduling, described the current process in detail, explained 
the methodology used and system developed, outlined the proposed planning and scheduling process, and identified some additional enhancements that could further improve the process.

One of the driving factors for selecting this topic was my personal conviction to do something more than add a brick to the wall of research, but instead to make a change and improve the process. This is industrial engineering after all! 


\section{Chapter 2: Literature Review}

\section{Overview and Classification}

University planning and scheduling literature often focuses on one of these 3 categories: planning, assignment of courses to faculty, and course scheduling. The main focus of the literature reviewed center on the timetable problem and a few course assignment papers.

There has been a reasonable amount of research done on the university timetable scheduling problem. The basic form of the timetable problem is easy to understand: assign each course section to a timeslot so that all constraints are satisfied and optimize a set of objectives. However scheduling under constraints hard or soft are complex tasks, having an NP-complete degree of complexity. In literature, there are many different algorithms and approaches that have been applied to address the course scheduling problem:

- Optimization based techniques

○ Integer Programming

- Dynamic Programming

- Goal Programming

- Heuristic Techniques

- Simulated Annealing

- Particle Swarm Optimization (PSO)

- Genetic Algorithms (GA)

- Evolutionary Approach

- Greedy algorithm 
○ Hill-climbing

- Local Search

- Tabu Search

These methods come from a number of scientific disciplines like (Abdullah et al. 2007):

- Operations Research

- Artificial Intelligence

- Computational Intelligence

A large research area for scheduling is utilizing search techniques such as Genetic Algorithms or Evolutionary Algorithms, combined with Local Search algorithms or simulation [Arous et al. (1999), Burke and Newall (1999), Wang (2002), Wang (2003), Kanoh and Sakamoto (2004), Ghaemi et al. (2007), Abdullah et al. (2007), Abdullah and Turabieh (2008), Wang et al. (2008), Irene et al. (2009)]. These techniques, however may reach a feasible solution to the problem at hand, but typically have no guarantees on the quality of the solution and many have no analysis of performance gaps relative to optimality for toy problems. Based on the work done by Arous et al. (1999), genetic algorithms have proven to be efficient in solving NP-complete problems.

In "Recent developments in practical course timetabling" by Carter and Laporte (1998) the authors categorize course timetabling approaches into 4 categories. Global algorithms include integer linear programming (ILP), network flow formulations, and goal programming. ILP is often used on small size problems or with decomposition techniques to solve by means of standard ILP solver package. Constructive Heuristics include constraint logic programming (CLP), incomplete branch and bound, and the simplest heuristic of making sequential assignments while maintaining feasibility until 
this is no longer possible. Improvement Heuristics improve upon a feasible solution and techniques include simulated annealing (SA), tabu search (TS), evolutionary or genetic algorithms (GA). Interactive Systems include interactive procedures to produce families of solutions under different constraints or preference weights.

In "A comparison of Course Scheduling Methods" by Ojha and Walker (2000) the authors categorize and compare four types of methodologies for solving course scheduling problems. They conclude that Greedy algorithms are flexible and efficient but their results are quite poor. Hill Climbing is flexible and gives better numerical results but takes more processing time to complete. Tabu Search is flexible and produced the best results efficiently. They were unable to use Linear Programming (LP) on a real set of data, but report that it is capable of generating very good results based on a toy set of data. LP however is not very flexible, is difficult for non-experts, and requires commercial solvers for large problems.

\section{Summary of Related Literature}

In "A Mathematical Programming Model for Faculty Course Assignments" by McClure and Wells (1984) they develop a method for faculty assignment where each variable represents a full teacher schedule and the problem is formulated as a set partitioning problem with side constraints.

In "Constructing a course schedule by solving a series of assignment type problems" by Hertz and Robert (1998) presents an approach that was similar to the one presented in this thesis in that it decomposes the problem into a series of smaller similar problems however, in this paper it was decomposed into many more pieces. The solution generated is satisfactory, but not optimal. 
Badri et al. (1998) combines both assignment of courses to faculty and assignment of courses to the timetable into one model. Faculty preferences are incorporated in a 3 levels and goal programming is used to solve the problem. Each faculty member defines 3 timeslot preferences are for each course and 3 course preferences for each timeslot. This creates a limited solution space; however since course conflicts are not taken into consideration, this isn't an issue.

In "Quantitative Modeling and Technology Driven Departmental Course Scheduling"by Boronico (2000) the author addresses a much larger problem. Simulation is used to forecast student demand and then fed into a hierarchical mathematical model. The assignment phase is modeled as a goal program with three goals: minimize number of unassigned courses, minimize additional preparations, and minimize additional days when faculty must teach. This case is more than double in size of the IME case.

Pesenti (2002) completed a thesis titled, "Decision Support Systems for University Course Scheduling". This work was centered on the development of a tool that would help the scheduler, but it wouldn't replace the decision-maker. The resulting database from the research allowed the user to input all the data required for the scheduling process and then the scheduling user assigned the desired timeslot to each course as well. The database allowed the user to run reports to view the information in a tabular format. It appears that there was no automated scheduling functionality. Pesenti highlighted a few special circumstances that he came across that caused complication in the development of the decision support system (DSS) and due to these conditions, the system that was built for the thesis was unable to detect scheduling conflicts.

- One course can be assigned to multiple instructors. 
- There can be multiple lab rooms assigned to one class.

- Multiple classes can be taught by the same instructor at the same time. For example undergrad and grad levels might be mixed.

- Assignment of independent courses that don't have a designated time on the schedule.

"Preferences Based Decision-making Model (PDM) for Faculty Course Assignment Problem" by Parthiban et al. (2004) presents a decision support system using Analytic Hierarchy Process (AHP).

In "University Course Scheduling System (UCSS) - A UML Application with Database and Visual Programming" by Fang (2005) a constraint based decision support system is designed and does not automatically solve for a solution.

In "Using information on unconstrained student demand to improve university course scheduling" by Thompson (2005) the author builds on his previous paper Hinkin and Thompson(2002) and improves the planning process. He concludes that determining student demand should be collected thru surveys instead of assuming which sections students need. We conducted some student surveys to get input for tech elective interests, but this can be a future extension and implemented more thoroughly for required courses.

Abdullah et al. (2007) applied genetic algorithms (GA) and sequential local search to generate a course timetable. Abdullah selected GA as a well-suited tool for university course timetable problem because it is used to search large nonlinear solution spaces where there is a lack of expert knowledge or it is difficult to encode. Also, GA doesn't require any gradient information and it evolves from one population to the next. GA produces more than one optima rather than a single local one. Local search was used 
within the GA to improve the quality of the solution. The developed algorithm was applied using Matlab. The results show that the proposed algorithm is able to come up with a feasible solution for each case tested and a stable state is reached after several iterations.

Ghaemi et al. (2007) applied Modified GA and Cooperative GA to solve the university timetable scheduling problem. Two approaches are applied in order to achieve the main goal of minimizing the number of conflicts in the timetable. Ghaemi et al. states that although GA approaches provide good solutions they require larger execution time. They have found that as a trend, those that integrate a two-stage strategy where feasibility is first evaluated and then soft constraints are optimized using operators that restrict the search to feasible areas of the search space typically outperforms the algorithms that evaluate both sub-problems at the same time thru the use of weightings in the evaluation function. They also pointed out that there are plenty of works researching algorithms specializing in optimization of soft constraints however there has been less focus on producing algorithms that specialize in finding feasibility in the first place.

\section{Software Products}

There are several software products that are available on the market and a couple were reviewed, however it was difficult to understand the undying methodology used in each package to solve the scheduling problem.

Orologio Class Timetabling System is a computer application, allowing you to schedule class timetables quickly and accurately. According to Orologio, it is unique because it automatically builds the timetable for the user. The program does not use preference to derive an optimal solution, but allows the user to create many timetables 
because of the fast processing and then the user can select the one that fits best. Orologio states that this approach saves time, decrease costs and provides better results. There are several versions of the software available: Standard, Advanced, Professional. The cost of Orologio ranges from $\$ 350$ for standard and $\$ 1,100$ for Professional and is available at: www.antinoos.gr/en/orologio.htm.

Thoughtimus sells ScheduleWhiz® Academic course scheduling (timetabling) software for post secondary educational institutions such as universities and colleges. This product was once known as ScheduleExpert in the research paper by Hinkin and Thompson (2002). This software allows users to create schedules that satisfy faculty requests, maximize faculty utilization, and avoid student conflicts. The price of the ScheduleWhiz software is $\$ 1,320$ per year for a single user license that can schedule up to 100 sections and is available at www.thoughtimus.com. 


\section{Chapter 3: Current Process}

This case study focuses on the planning and scheduling process for the Industrial and Manufacturing Engineering department at Cal Poly. During the winter quarter, the department conducts the majority of the planning for the following academic year. Typically at this point the course offerings are determined and the courses are assigned to the tenure and tenure track faculty for the following year. At this time the time table for the fall quarter is also created. Typically the Lecturers are assigned and timetables are determined and entered into the university scheduling system 2 or 3 quarters prior to the term start. Leading up to the start of registration for each term, the department makes minor tweaks as needed.

\section{Assignment}

The current process for the IME department to assign courses to faculty members is a manual technique. The department scheduler looks at the courses that are going to be offered during a particular quarter and has a list of faculty who typically teach each course. There are a few assignments that are the same every year and those are typically done first. Next other courses are placed manually based on historical assignments and the scheduler experience with faculty preference. During the process WTU (workload teaching units) that are assigned to each faculty are tracked manually to ensure each faculty load has an acceptable load. If there isn't any of the typical faculty available to teach a course then the scheduler refers to the preference matrix to look for an alternate option. This situation often occurs when a faculty member goes on sabbatical or other type of leave. Sometimes it is can be a challenge to shift courses around so that the assignment is acceptable. 
Once the assignment is complete, the scheduler reviews the WTU and manually inputs the schedule into a spreadsheet to create a WTU and assignment report to review with chair and faculty members. If any changes are necessary, the scheduler shifts assignments around until an acceptable assignment is agreed upon.

One downside of this manual approach is that since it is a manual process, it is potentially susceptible to human error and unbalanced preferences. Often the assignment is not created to maximize and balance preferences across the department. Because it is difficult to manually maximize total preference for the department sometimes the most particular faculty members might get their perfect assignment while the faculty members who have historically been the most adaptable and flexible are often the first ones assigned to a much less preferred course. There are often situations where courses need to be shifted around to avoid assigning a very undesirable course to a faculty member. When these shifts need to take place the manual approach cannot evaluate all the alternatives.

Stepping away from the particular department studied, another potential downside of the manual assignment approach in general is the vulnerability to bias and personal preferences of the individual creating the manual assignment. In a manual approach, the scheduler ultimately has a lot of power and control over the department. The course assignments have a huge impact on faculty members' lives and job satisfaction as well as students.

\section{Scheduling}

Once each course has been assigned to a faculty member, the schedule is created to assign a timeslot to each course. The current process of creating the timetable is a 
paper based scheduling technique. The majority of the scheduling is performed on a series of schedule templates.

The scheduler collects availability data from each faculty member on the scheduling template so that a schedule can be created without conflicts. The scheduler prepares a paper schedule template form for each lab, each faculty, each upper division course level, and manufacturing courses. Typically the scheduler creates templates for the following areas:

- Course Level
○ 300 Level
- 400 Level
- 500 Level

- Lab rooms in department control
○ 192-105
○ $192-220$
- 192-221
○ 41-103
○ 41-109

- Each faculty member to be scheduled

These are the areas that the scheduler wants to avoid conflicts. By creating a schedule form for each of these areas, the scheduler can visually see any conflicts and reschedule accordingly. In addition to the conflict areas above, it is important to avoid conflicts with required courses outside the department. These conflicts are indicated on the appropriate course level schedule form. 
Once the schedule forms are created, the scheduler starts the scheduling process. The scheduler typically begins with the most constrained courses and faculty and places those first since they have the least flexibility. Next, labs are placed primarily on Monday, Wednesday, and Friday to leave Tuesday and Thursday mostly open for 80 minute lecture timeslots. The scheduler relies on the previous year's schedule as a guideline for the course timetable. Prior to placing any course on the timetable, the scheduler verifies the availability of the timeslot and tries to ensure there aren't any conflicts with other courses at the same level, room conflicts or faculty availability conflicts. The timeslot should also fit in with the university defined timeslots. As each course is placed on the timetable, the scheduler marks it on the appropriate faculty member sheet, the course level sheet, and the lab room sheet as needed.

With an eraser close at hand, the scheduler repeats this iterative process with one course at a time and each time trying to schedule the next most constrained course. Since the process is very iterative, there are changes along the way that trickle down and impact several courses. As this happens, the scheduler might either start over, shift courses around, or compromise and allow a conflict of some sort. The figures in Appendix A show examples of the course level and room schedule forms that are used in the manual schedule process.

The biggest downside of the manual scheduling approach is that the scheduler cannot look at every combination of schedules and evaluate which one is best. Since the scheduler cannot look at every combination, it is likely that an overlap in courses is necessary in order to schedule all the courses into the timetable. Some quarters might work out with minimal overlap at the class level; however other quarters result in overlaps in critical courses. These overlaps impact the student's ability to take their 
desired courses. An example of manual schedules that are not ideal is spring 2010 which has 3 critical overlaps. The overlaps in the spring 2010 term are:

- IME312, a required IE course and IME 335, a IE course required for the 0509 catalog

- IME 407, an IE required course for the 05-09 catalog and IME 437, an IE elective

- IME 443, an IE required course and IME 437, an IE elective

The IME 437 LAB overlap with two required IE courses resulted in an enrollment of 6 students in IME 437. This is a perfect example of how a poor schedule can impact the utilization of sections. Another downside is the potential for human error. With the manual scheduling approach, it is not uncommon that two courses conflict in the same lab or that save class level courses overlap as seen by the spring 2010 case and this might be caused by lack of scheduling options or by error. These errors potentially increase in frequency with distractions so it is critical that the scheduler have $100 \%$ focus time when creating the timetable to minimize the chance of error. Lack of flexibility is another disadvantage of manual timetable creation. Since the scheduler cannot come up with every combination of timetables, there is a chance that faculty preferences cannot be met with the timetable developed. If any changes are necessary, reworking the timetable is a very laborious task so changes are highly discouraged. 


\section{Chapter 4: Methodology}

\section{Methodology Overview}

The research and system development methodology followed in this thesis is outlined in Figure 2. It started with a problem definition phase where the needs of the department were evaluated and the current process was understood. With this understanding, research was conducted to understand how other researchers were addressing this problem. With this understanding, a system was designed and real life inputs were gathered and populated into the tool. As the model was constructed, we evaluated alternative methods and succeeded with an integer programming approach which was much simpler than the design I was initially considering. The prototype of the system was developed and testing began. With all the real inputs for the 2010-2011 academic year, the assignment was tested. The scheduling was tested with the real inputs for the fall 2010 term. The $2010-2011$ assignment solution was evaluated by the department and the faculty members provided their feedback and changes were made. The fall 2010 schedule was also reviewed by the department and with minor changes; it was distributed to faculty members for review. There were very minimal changes needed based on the faculty member input and these were mainly due to weak points in faculty preferences and availability data. With a tested design, the tool will be refined slightly for the next scheduling term and then will be implemented into the department planning and scheduling process. 


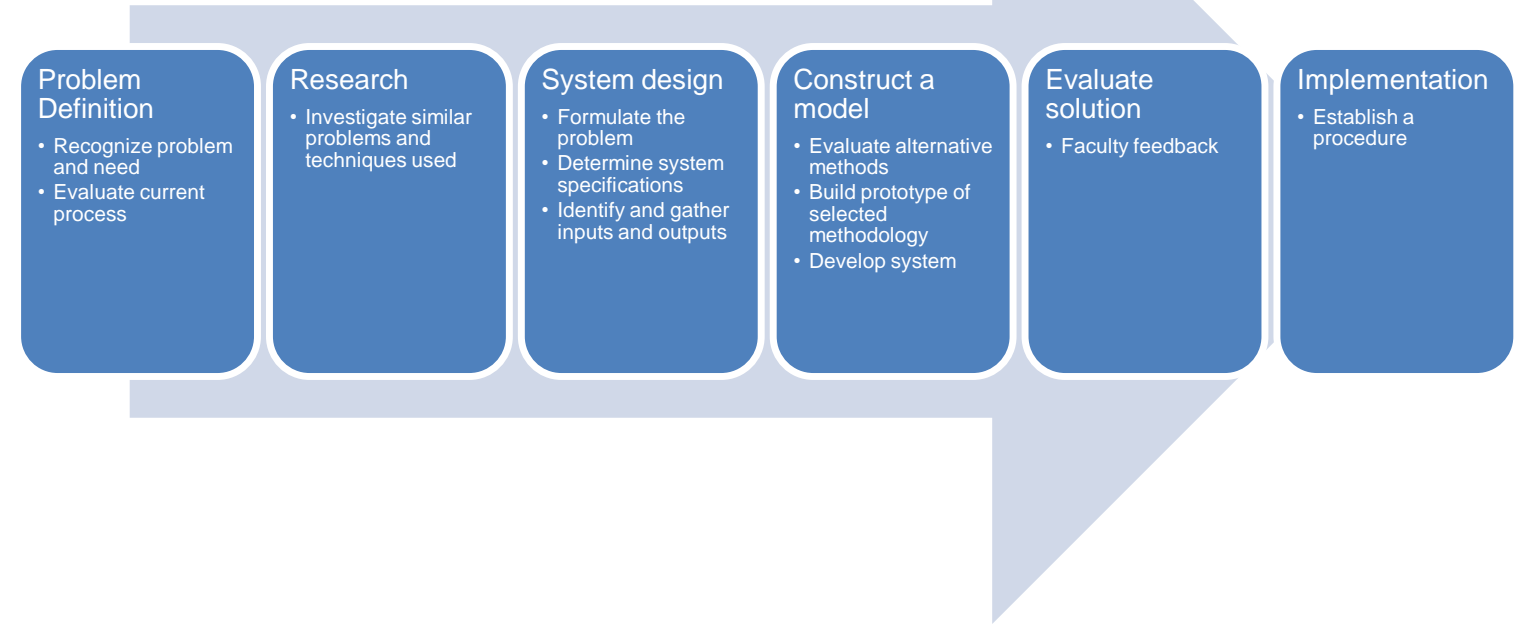

Figure 2: Research Methodology Overview

\section{System Overview}

This systems approach to planning and scheduling has taken into consideration the entire planning and scheduling process with many inputs and outputs. Planning and scheduling should not be looked at independent of other steps in the process or independent of the impacts they have on the faculty and students. These impacts are taken into consideration not only as hard constraint needs, but also as preferences in the model. An end to end system was created to aid from the initial stages of course offering planning to the final timetable reports for department approval. This is accomplished using a mix of manual decision techniques for the course offering planning and linear programming transportation models for the assignment and timetable scheduling. This system is aided with pieces of automation for process improvement.

In order to create an acceptable and adoptable solution, it is critical to take into consideration the faculty preferences. Many other solutions found in research do not 
take into consideration the level of preferences that have been incorporated here. Typically in research, it was found that the basic needs were incorporated as hard constraints. In reality, preferences are not strictly black and white as they are when modeled as hard constraints. One's preferences actually are shades of gray. For example a faculty member might have 3 courses they really want to teach, another 6 they like to teach, a few more they could teach if they needed to and the remaining courses offered they are not qualified to teach. Without these shades of gray there isn't any distinguishing between courses that the faculty love and like as well as between courses they dislike and are not qualified for. While an ideal solution does not require faculty members to instruct any course they dislike, there might be occasional circumstances where this is needed and the distinction between dislike and not qualified is necessary.

These shades of gray also appear in the timetable scheduling. A faculty member might prefer to teach from $10 \mathrm{AM}-3 \mathrm{PM}$, but 9 - $10 \mathrm{AM}$ is acceptable also. Without incorporating these shades of gray one of two things happen. One alternative is the faculty member constrains their availability more than necessary because there isn't an avenue to communicate the preference. This has potential to create an over constrained problem. The other alternative is the faculty member opens up their availability on their schedule, but there is potentially less satisfaction with the resulting schedule. While the entire department ultimately has to work together to offer the necessary courses at a variety of times so that the students can create feasible schedules to make progress on their degree, it is critical to recognize and respect the preferences of the highly educated, hard working faculty members delivering this instruction. When a faculty member has an assignment that fits their expertise plus a schedule that fits their routine, 
it creates higher job satisfaction. This approach has blended preferences into the objective functions in order to incorporate the truly fuzzy nature of individual preferences.

This system is designed to address the entire planning process from determining course offerings up to the point of creating a timetable report. By incorporating the entire process into one system, it minimizes error, data input and saves time. Due to the nature of the planning process, it is not feasible to create an automated process from start to end. Tools and reports were provided to aid in decision making so that the department could makes course offering decisions based on budget, student population and demand, historical data, faculty interests, and flow charts. Once the required course offerings were determined, there were some flexible courses that could be placed in any quarter based on demand and capacity. This allowed for some flexibility in the course offerings but the student load at each grade level and program had to be evaluated carefully based on the term each flexible course was assigned to. While the assignment of faculty to course section was more of an automated approach, the tool still allowed for the flexibility of manual changes that didn't conform to the hard constraints. Once the assignment was complete, the scheduling process was again an automated process with the ability to make manual changes to the output as necessary. In designing the system, it was created to accommodate the manual changes that inevitably occur in this environment.

For the complex task of assignment and timetable scheduling, a transportation linear programming model was developed to maximize preferences and avoid conflicts.

\section{Course Offering Planning}

The system was used to aid in the planning of course offerings of the case study planning cycle by bringing visibility to the historical data and decisions that were being 
made. There are many inputs to the planning phase of scheduling as depicted in Figure 3.

\section{Planned Course Offering Inputs}

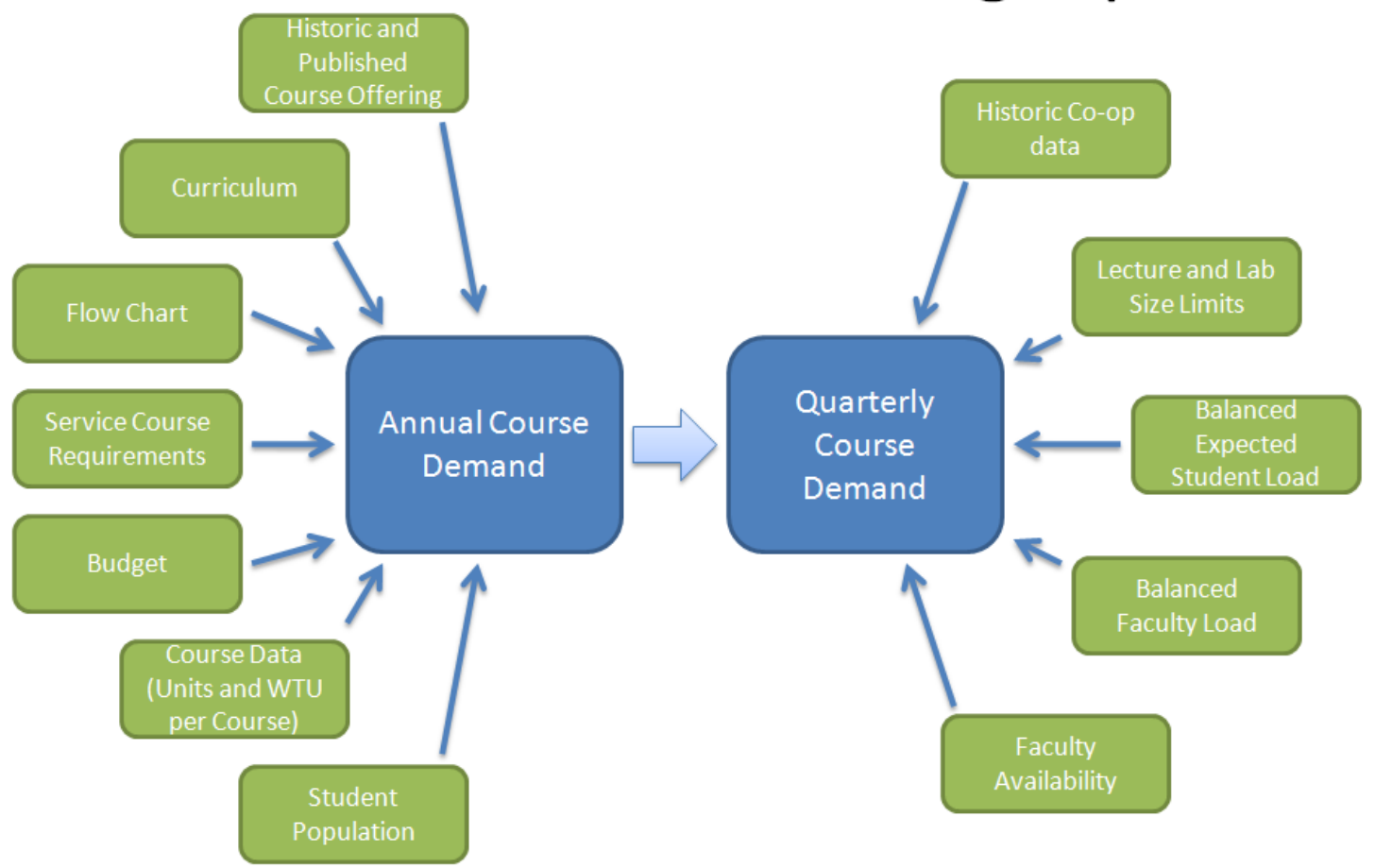

Figure 3: Planned Course Offering Inputs

The worksheet as shown in Figure 4: Planned Course Offerings brings together the courses, the catalog requirements, the history, and provides a tool for the scheduler to input the planned course offering. As the scheduler inputs the number of sections and size of sections planned, the tool automatically reports out the WTU and SCU (student credit unit) of the planned offering. This real-time feedback allows the user to experiment with what-if scenarios for different options. The report in Figure 5: Planned WTU Summary was created to report the WTU of the proposed offering to ensure that the WTU is within budget. The WTU per quarter was also reported to ensure it was in 
line with faculty capacity at the quarterly level. The costs have been removed in the included figure; however the report is set up to provide this feedback to the user.

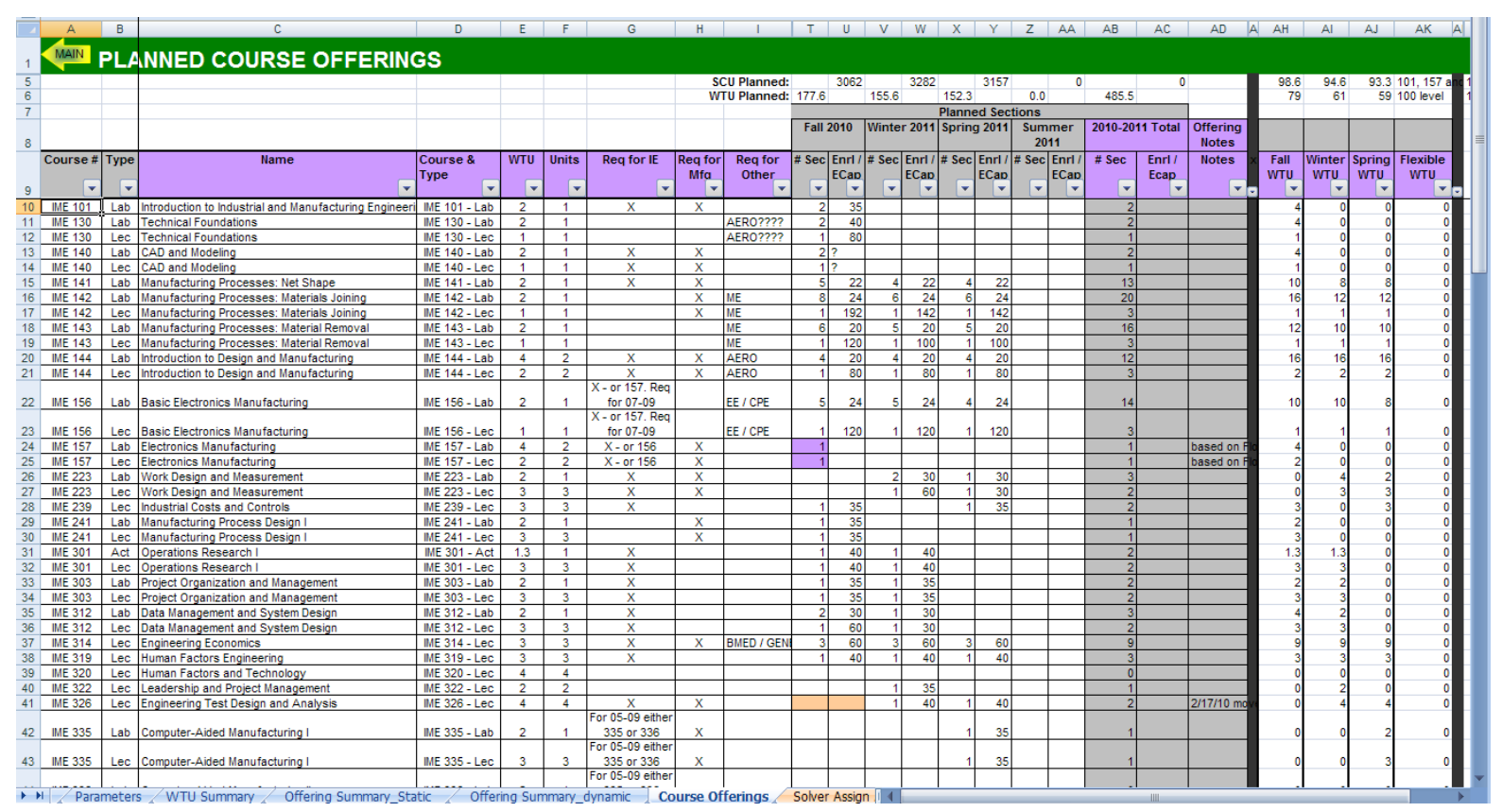

Figure 4: Planned Course Offerings

\begin{tabular}{|r|r|r|r|r|r|r|}
\hline & \multicolumn{2}{|c|}{ B } & D & F & G \\
\hline \\
\hline
\end{tabular}

Figure 5: Planned WTU Summary 
This worksheet and report allows the user to easily input and determine the WTU and budget impacts of the course offerings. The planned course offering are then an input to the assignment of faculty members to courses. Again, for the course offering planning, this tool is just an aid to the scheduler and scheduling committee. They still need to incorporate department policy, flow chart, insight of changes to historical trends, knowledge of current and forecasted student population and their experience into the planning of course offerings.

When planning for 2010-11 academic year, sensitivity analysis was performed to evaluate the balance of tenure and tenure track faculty and upper division courses offered.

\section{Assignment}

\section{Overview}

The goal of this feature is to provide a Microsoft Excel and Solver based assignment program to the department scheduler for the purpose of creating a good "first pass" plan for assigning professors to class sections. This will enable a good starting point for term scheduling. This function is currently done by hand, and often results in multiple iterations to meet preferences.

\section{Inputs and Constraints}

The assignment dashboard requires 3 major inputs: faculty workload targets, faculty course preference, and planned course offerings as shown in Figure 6. 


\section{Faculty to Course Assignment Inputs}

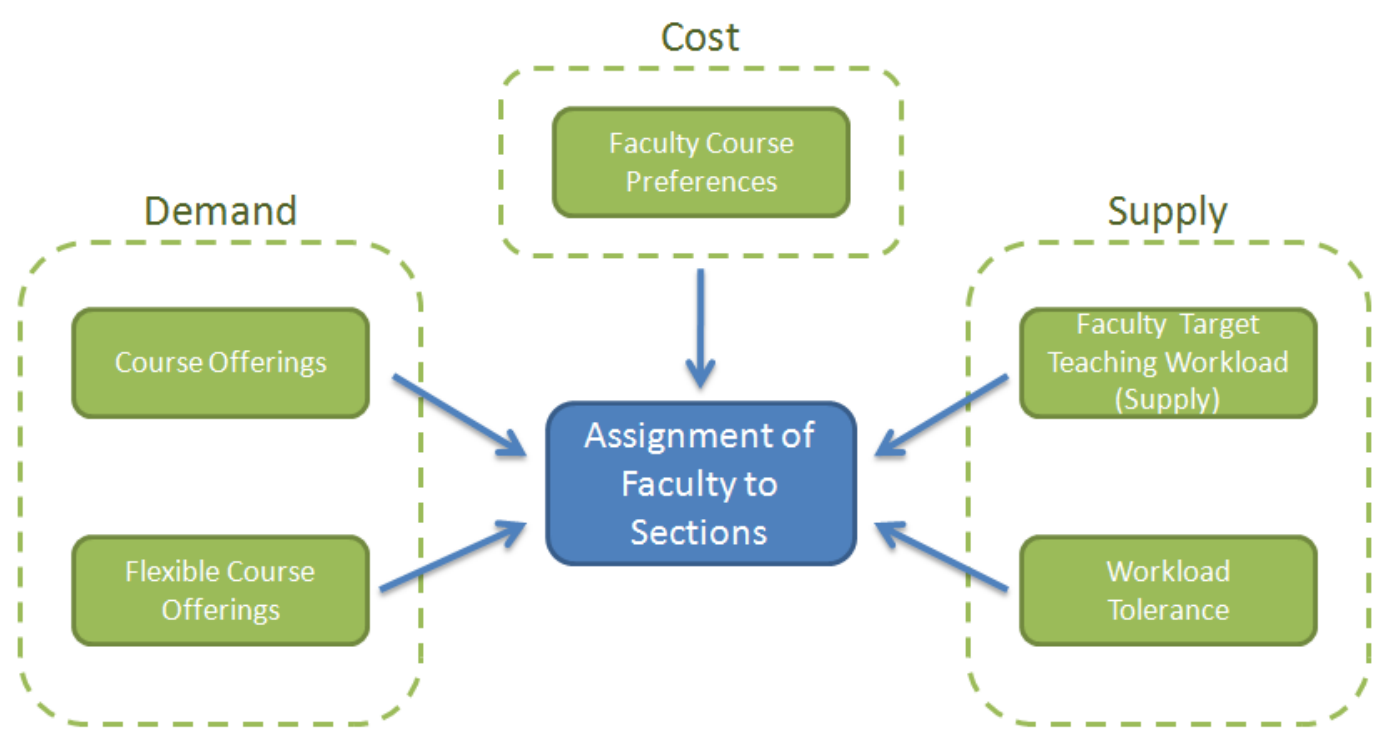

Figure 6: Faculty to Course Assignment Inputs

These sections can be viewed on the overall assignment dashboard view in Figure 7.

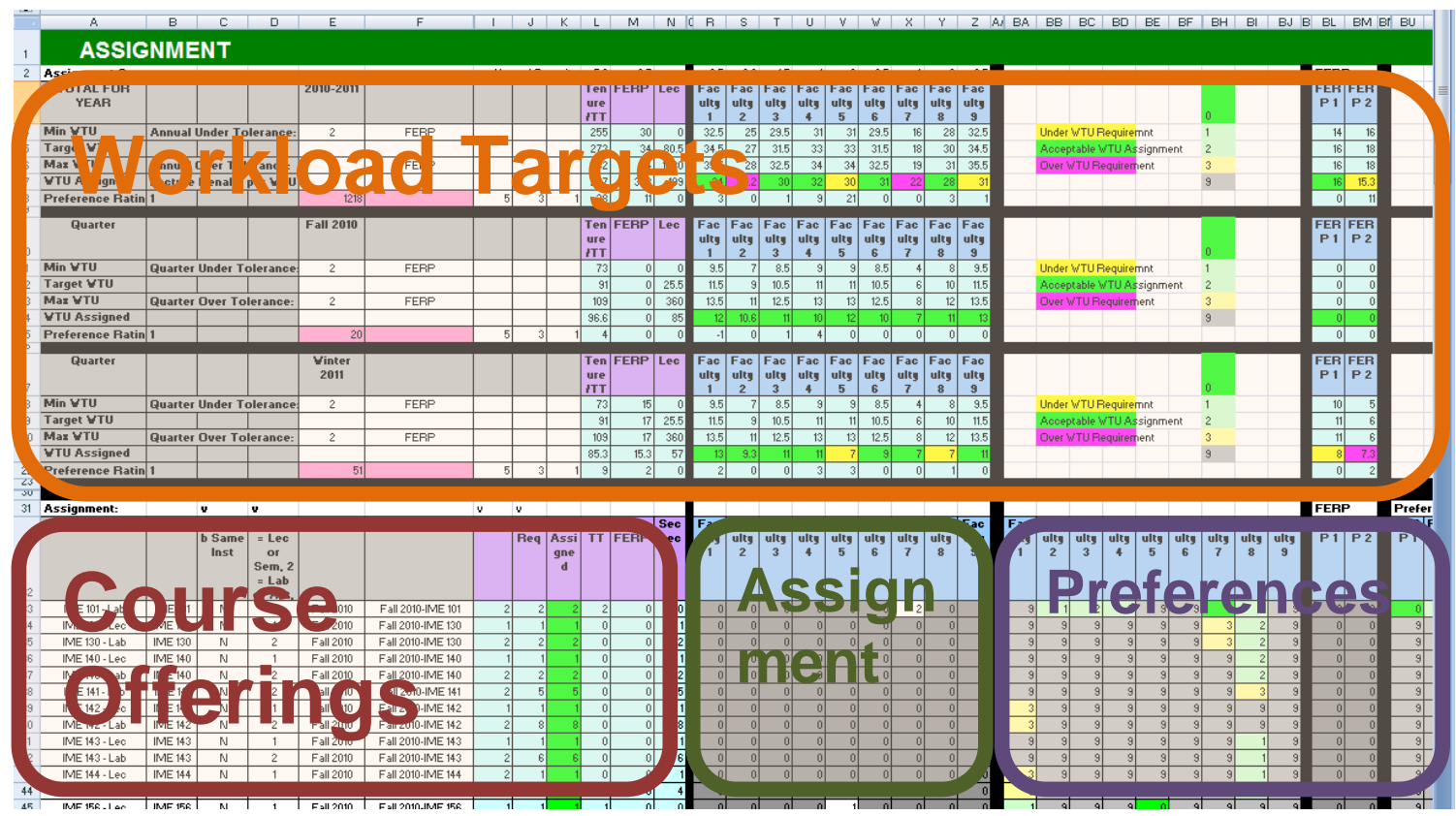

Figure 7: Assignment Dashboard - Overall 
Faculty workload targets are measured in WTU's. This is a variable constraint that can be adjusted by the user to reflect the necessary class load for each professor. Figure 8 shows the WTU input to the assignment model for Tenure/Tenure Track (TT) Faculty and FERP (faculty early retirement program) faculty. The top box in the figure highlights the min, target, and max total WTU for each faculty member for the academic year. The min WTU is determined by subtracting the annual under tolerance from the target and the max is determined by adding the annual over tolerance to the target. The WTU assigned by the LP will fall in this range for the year. The second, third, and forth boxes are highlighting the WTU targets for the fall, winter, and spring quarters. The quarter level targets also have under and over tolerances associated with them to create a min and max target WTU per quarter. More fluctuation is allowed at the quarter level than the annual level to allow for more course configurations in a particular quarter while tightly controlling the total workload. 


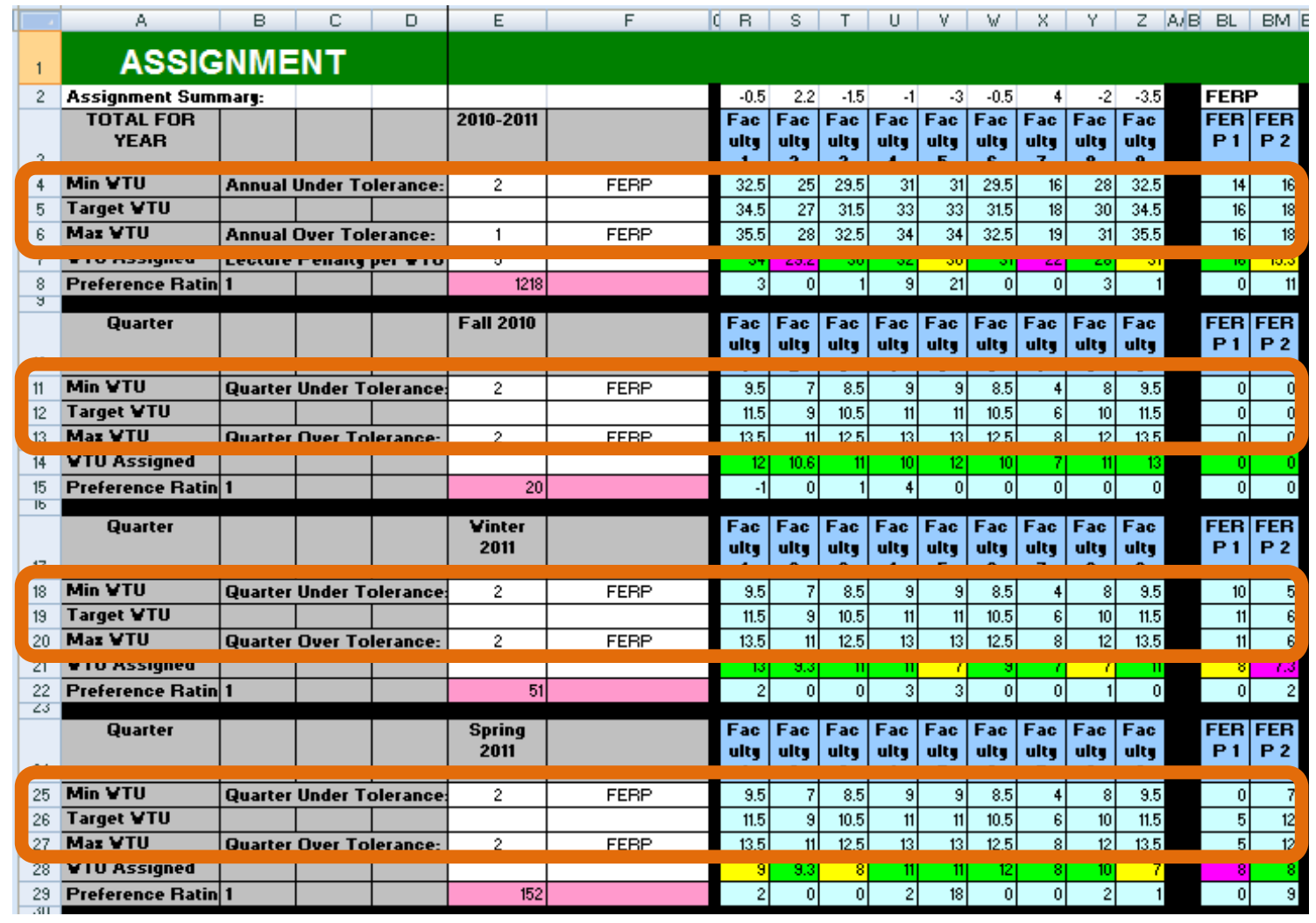

Figure 8: Assignment Dashboard - Faculty Workload Targets

Faculty course preferences are defined so that professors are assigned to classes they prefer to teach, and eliminate classes that they cannot teach, or should not be assigned to. Each faculty member defines their course preferences for each course that is offered on a scale of 0 to 3 and 9 . Some sensitivity analysis was performed around the preferences and it was determined that because the nature of course preferences is not linear, the scale is created from 0 to 9 with acceptable preferences from 0 to 3 . The definitions of these preference levels are:

- 0 : Faculty member is the typical professor for the course and would really like to continue to teach the course. The faculty member delivers a high quality of instruction on the topic and the students benefit from having this faculty member assigned to the course. There are no political issues. This is the ideal assignment. 
- 1: Faculty member is proficient at teaching the course and enjoys the topic. Faculty member delivers quality instruction to the students. Faculty member is very interested in teaching course, but might not be the typical instructor. Faculty member doesn't need any prep time prior to quarter. This is a good assignment.

- 2: Faculty member is willing and interested in teaching topic but hasn't taught it previously or recently. Needs about 1 quarter of prep time to refresh on material. Due to new or refresh prep, the workload on the faculty member will be higher. Faculty member is capable of delivering quality instruction to students.

- 3: Faculty member would prefer to not tech this course, but if the team needs them to they are capable. Approx 2 quarters of prep time prior to term to get more comfortable with material. Since this is not a preferred topic, the quality of instruction will likely decrease slightly due to lack of passion on the topic.

- 5: Faculty member would really prefer to not teach the course. Very uncomfortable with topic. Would need 3 quarters to prepare for quarter. Instruction quality will be impacted. There might be some political issues with this assignment.

- 9: Faculty member is not capable of teaching the course.

As a general rule, the tenured faculty should be excluded from teaching 100 level courses, so a value of 1 is added to their preferences.

The course preferences are inputted into a separate table that will be discussed later, however they are displayed as part of the assignment dashboard as highlighted in Figure 9 and used in the course assignment formulation. 


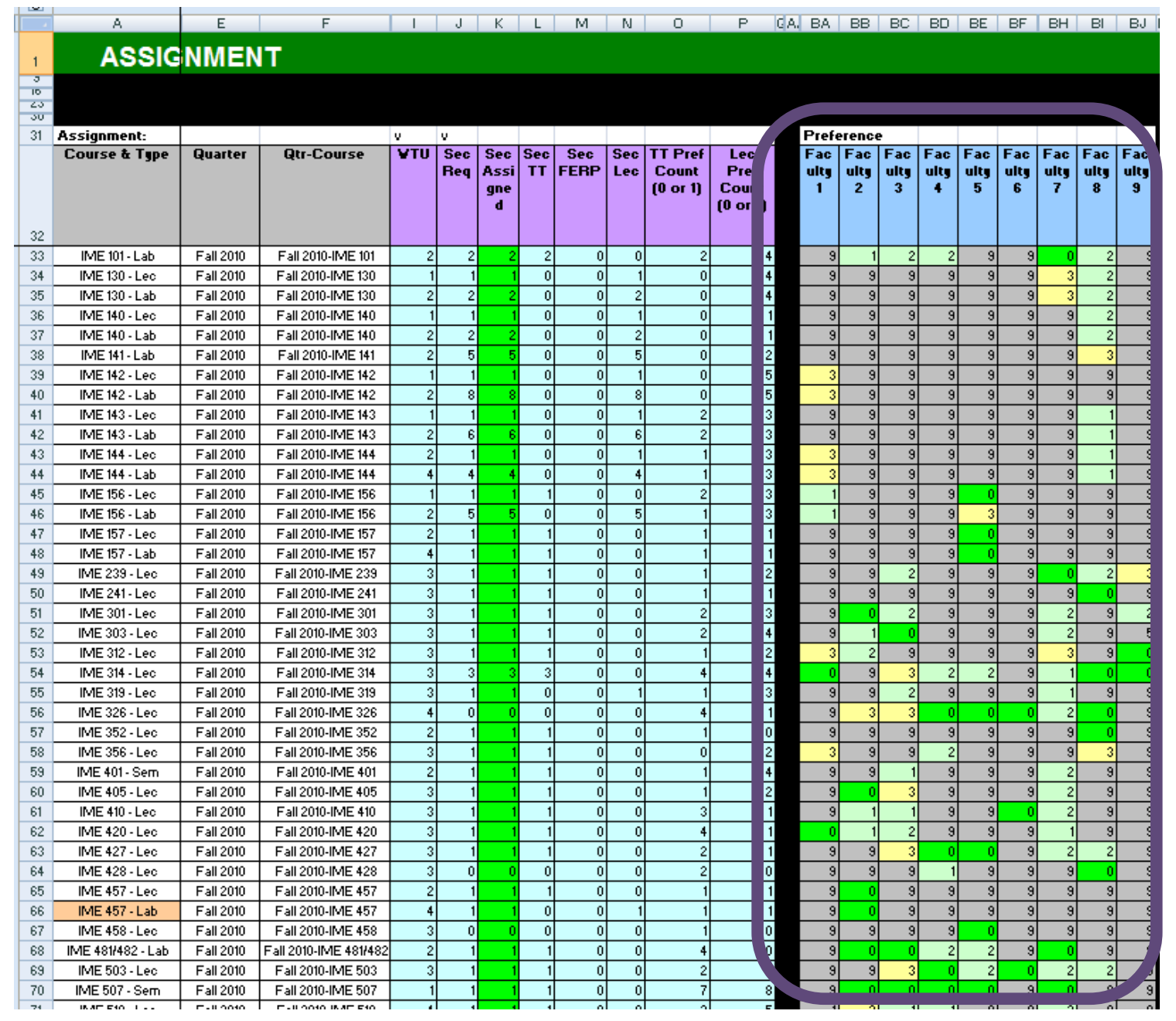

Figure 9: Assignment Dashboard - Faculty Preferences

Course offerings allow the user to see which courses are planned for each quarter and how many sections need to be assigned. The course offerings are updated from the planned course offering dashboard. The course offerings for the entire academic year are listed out with a separate section of rows for each term. Lab and activity sections for courses that are always assigned the same instructor for lab and lecture are separated out so that the assignment formulation can handle these appropriately. For reference and calculations, the WTU value of each course is also included. Additional preference statistics are included in the course offering section to report the number of faculty members have a preference of 0 or 1 for the particular course. This allows the user to 
review any courses that are being offered that don't have enough faculty members with preferences to teach that course.

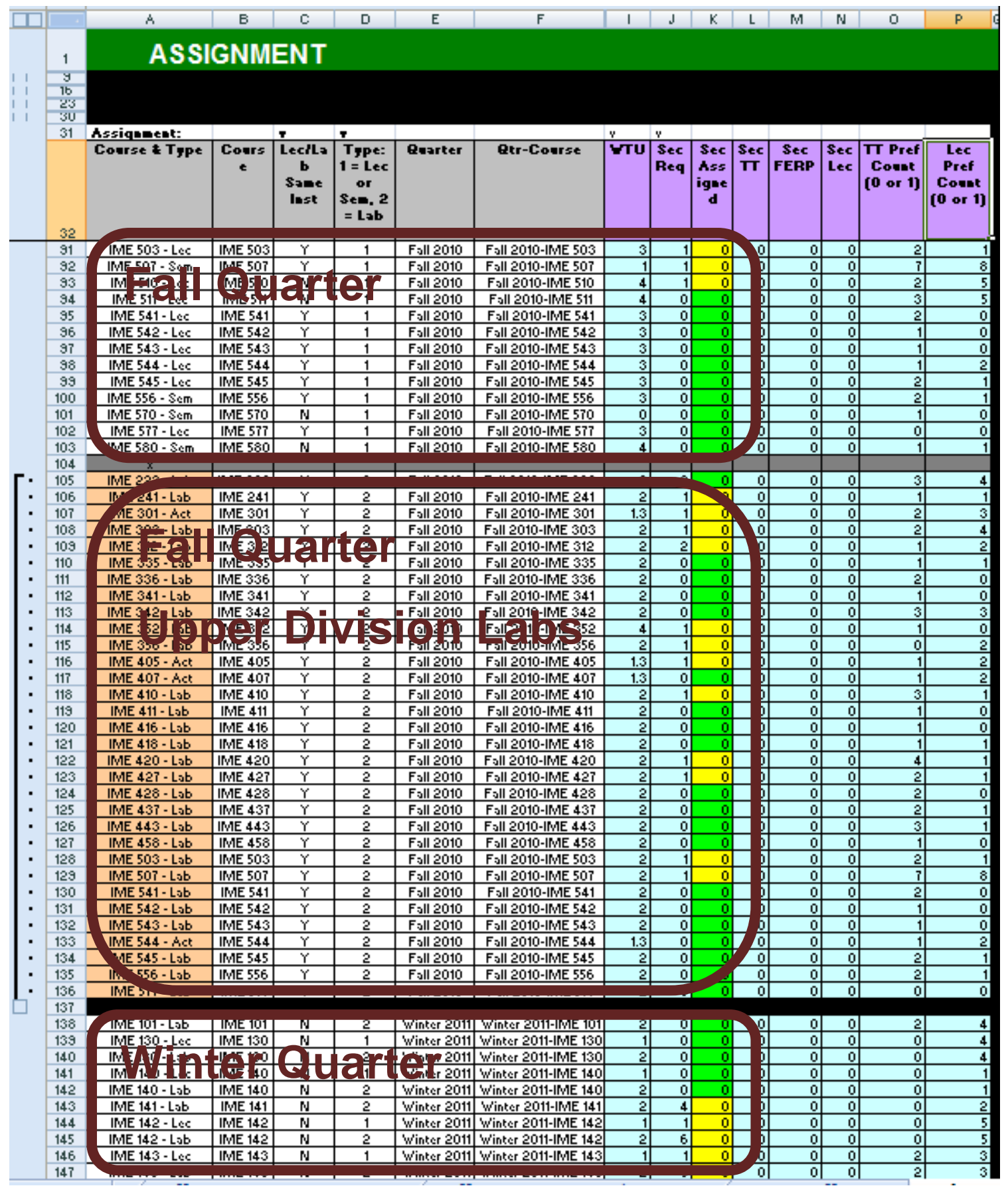

Figure 10: Assignment Dashboard - Course Offerings 


\section{Objective and Approach}

The goal of the assignment problem formulation is to minimize the total professor dissatisfaction while satisfying the constraints of minimum and maximum workload (WTU's) for each professor and assigning all the required sections for the term. Course preference is made artificially high ( 9 value) for courses that should be excluded from any professor's list of classes they can/should teach. Additionally, for a preferentially assigned course, a 0 value can be assigned to ensure that class is taught by a particular professor.

Tenure / tenure track faculty (TT faculty), FERP faculty, and lecture faculty are separated so that the assignment of courses to each group can be prioritized or done in stages as necessary. Each group has a section with the assignment output and preferences.

Lecture pool professors have a lower (typically 0) minimum WTU load compared to tenured faculty. This ensures that the minimum contracted WTU requirements for tenured faculty are met while allowing the overflow courses to be taught by lecturers.

The assignment problem is setup in Excel and solved as an integer programming problem using Premium Solver add-in for Excel.

\section{Model Definition}

Model Description

The assignment of sections to faculty members is solved as a transportation problem.

Notation Legend 


$$
\begin{aligned}
& c=\text { course } \\
& f=\text { faculty } \\
& q=\text { quarter }
\end{aligned}
$$

Data

$p_{c f}=$ Level of dissatisfaction of faculty $f$ assigned to course $c$ where the scale is defined as:

$$
\begin{aligned}
& 0=\text { very strong interest in teaching course } \\
& 1=\text { preferred course } \\
& 2=\text { acceptable course if needed } \\
& 3=\text { prefer not to teach the course } \\
& 5=\text { very strong desire not to teach course } \\
& 9=\text { absolutely not qualified to teach course }
\end{aligned}
$$

$\mathrm{WTU}_{\mathrm{c}}=$ the workload as defined by the weighted teaching units of course $\mathrm{c}$

$t_{f}=$ Average quarterly target teaching load in WTU of faculty f taking into consideration the contracted WTU minus any release time and advising load

$$
\mathrm{S}_{\mathrm{cq}}=\text { Number of sections required of course } \mathrm{c} \text { in quarter } \mathrm{q}
$$

Variable Definition 
$x_{\mathrm{cfq}}=$ Number of sections $(0,1, \ldots, 7)$ of course $\mathrm{c}$ assigned to faculty $f$ in quarter $q$ where,

$$
\begin{aligned}
& c=1, \ldots, 70 \\
& f=1, \ldots, 15 \\
& q=1,2,3
\end{aligned}
$$

Objective Function

Minimize

$$
\sum_{c=1}^{70} \sum_{f=1}^{15} \sum_{q=1}^{3} p_{c f} * x_{c f q}
$$

\section{Constraint Types}

- For each faculty member and for each quarter, the assigned quarterly workload in WTU must be approximately equal to the quarterly target teaching load for the faculty member.

$$
\sum_{c=1}^{70} \mathrm{WTU}_{\mathrm{c}} * X_{c f q} \cong t_{f} \quad \forall f \text { and } \forall q
$$

- Assigned annual workload in WTU must be approximately equal to the annual target teaching load for the faculty member.

$$
\sum_{c=1}^{70} \sum_{q=1}^{3} W T U_{c} * x_{c f q} \cong 3 * t_{f} \quad \forall f
$$

- The number of sections of course $\mathrm{c}$ assigned in quarter $\mathrm{q}$, must equal the number of sections planned for course $\mathrm{c}$ in quarter $\mathrm{q}$. 


$$
\sum_{f=1}^{15} x_{c f q}=s_{c q}=\text { Section demand of course } c \text { in quarter } q \forall c \text { and } \forall q
$$

\section{Assignment Output and Results}

The Assignment Program delivers a reasonable first pass schedule of professor assignments. By using this program feature, the department scheduler can supply inputs of course requirements, professor workload, and changing professor preferences in minutes instead of hours. This delivers a result that meets more faculty preferences and enables faster turnaround time to develop the final assignment schedule. This flexible program can be adapted to any academic year or quarter, making it a valuable tool moving forward, and more than just a "one shot" affair.

The particular case that was evaluated didn't have a lot of flexibility and resulted in an assignment with a couple less desirable assignments due to the lack of faculty interested in instructing some of the 100 level courses. This created a situation with too much supply for the upper division courses and not enough demand (planned course offerings) due to the budget constraints. Some sensitivity was performed around the faculty course preferences and how that lined up with the course offerings. We determined that considering the overlaps in preferences there were a couple faculty members with limited preferences that didn't have enough courses with preferences less than or equal to 2 so assignments with preference of 3 were acceptable.

In the resulting assignment, the TT faculty preferences were weighted slightly higher than the FERP faculty and a penalty was assigned for WTU assigned to a general lecturer pool in order to minimize the cost of lecturers. For the academic year planning done in winter, assignments for the 100 level lecturers were pooled together under a 
staff position in order to minimize the number of integer variables in the model due to solver constraints.

Once the assignment program is run and the output is reviewed several tweaks can be done to modify the results if necessary. Preferences, target WTU, WTU tolerance, faculty group weighting can all be modified to create a more acceptable result if needed. Additionally, lab/lecture pairs can be split if needed to create the right balance of WTU for faculty members. The scheduling tool can make it very easy to make these modifications and re-run the assignment. If changes are necessary that don't conform to the constraints defined, the resulting assignment can be altered by manually manipulating the assignment output portion of the assignment dashboard highlighted in Figure 11. For the 2010-2011 term there were two manual changes made that assigned more WTU to faculty than allowed by the system. 


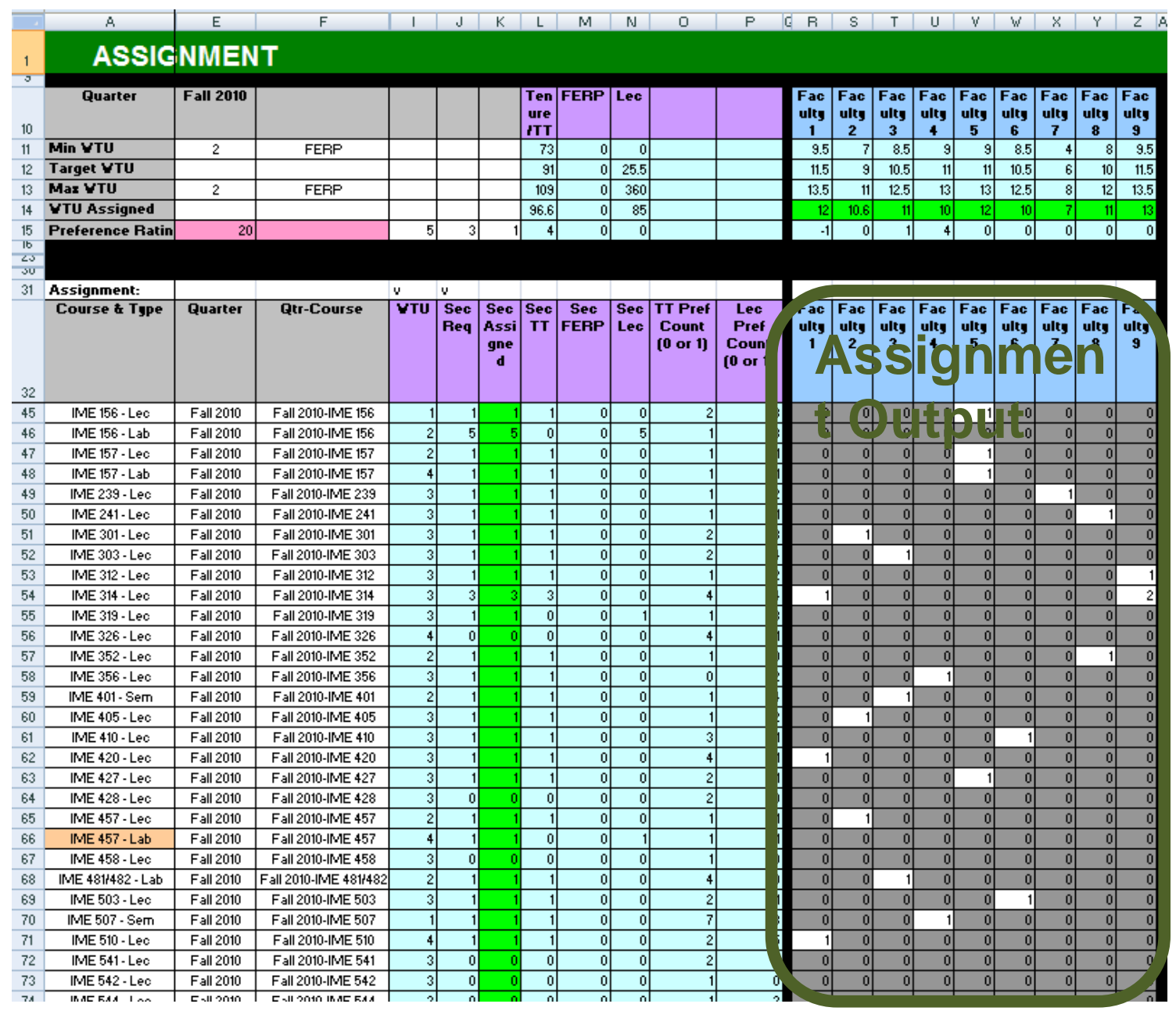

Figure 11: Assignment Dashboard - Assignment Output

Once an acceptable assignment is generated, output reports can be reviewed and distributed as necessary. Some of the available reports that were used are the Assignment WTU Summary as seen in Figure 12 that provides a summary of the total WTU vs. Target for each TT and FERP faculty member. 


\begin{tabular}{|c|c|c|c|c|c|c|c|c|c|c|c|c|c|c|}
\hline & & \begin{tabular}{|c|} 
Faculty \\
1
\end{tabular} & \begin{tabular}{|c|} 
Faculty \\
2
\end{tabular} & \begin{tabular}{|c|} 
Faculty \\
3
\end{tabular} & \begin{tabular}{|c|} 
Faculty \\
4
\end{tabular} & \begin{tabular}{|c|} 
Faculty \\
5
\end{tabular} & \begin{tabular}{|c|} 
Faculty \\
6
\end{tabular} & $\mid \begin{array}{c}\text { Faculty } \\
7\end{array}$ & \begin{tabular}{|c|} 
Faculty \\
8
\end{tabular} & \begin{tabular}{|c|} 
Faculty \\
9
\end{tabular} & \begin{tabular}{|c|} 
FERP \\
1
\end{tabular} & \begin{tabular}{|c|} 
FERP \\
2
\end{tabular} & Total & $\begin{array}{c}\text { Unused } \\
\text { Capacity: } \\
\text { Target - } \\
\text { Assigned }\end{array}$ \\
\hline Target WTU & TOTAL FOR YEAR & 34.5 & 27 & 31.5 & 33 & 33 & 31.5 & 18 & 30 & 34.5 & 16 & 18 & 307 & 8.5 \\
\hline WTU Assigned & TOTAL FOR YEAR & 34 & 29.2 & 30 & 32 & 30 & 31 & 22 & 28 & 31 & 16 & 15.3 & 298.5 & \\
\hline Preference Rating & TOTAL FOR YEAR & 3 & 0 & 1 & 9 & 21 & 0 & 0 & 3 & 3 & 0 & 11 & 9 & \\
\hline Target WTU & Fall 2010 & 11.5 & 9 & 10.5 & 11 & 11 & 10.5 & & 10 & 11.5 & 0 & & 1 & -5.6 \\
\hline WTU Assigned & Fall 2010 & 12 & 10.6 & 11 & 10 & 12 & 10 & & 11 & 13 & 0 & & 96.6 & \\
\hline Preference Rating & Fall 2010 & -1 & 0 & 1 & 4 & 0 & 0 & 0 & 0 & 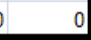 & 0 & 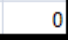 & & \\
\hline Target WTU & Winter 2011 & 11.5 & 9 & 10.5 & 11 & 11 & 10.5 & & 10 & 11.5 & 11 & 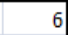 & 108 & 7.4 \\
\hline WTU Assigned & Winter 2011 & 13 & 9.3 & 11 & 11 & 7 & 9 & 7 & 7 & 11 & 8 & 7.3 & 100.6 & \\
\hline Preference Rating & Winter 2011 & 2 & 0 & 0 & 3 & 3 & 0 & 0 & 1 & 0 & 0 & 2 & 11 & \\
\hline Target WTU & Spring 2011 & 11.5 & 9 & 10.5 & 11 & 11 & 10.5 & & 10 & 11.5 & 5 & 12 & 108 & 6.7 \\
\hline WTU Assigned & Spring 2011 & 9 & 9.3 & 8 & 11 & 11 & 12 & & 10 & ) & 8 & 8 & 01.3 & \\
\hline Preference Rating & Spring 2011 & 2 & 0 & 0 & 2 & 18 & 0 & 0 & 2 & 2 & 0 & 9 & 34 & \\
\hline
\end{tabular}

Figure 12: Assignment WTU Summary

The assignment of courses to faculty report in Figure 13 lists the courses assigned to each faculty members each quarter. It reports the number of WTU assigned to each faculty member by quarter and course. This report can be distributed to faculty for schedule review.

\begin{tabular}{|c|c|c|c|c|c|c|c|c|c|c|c|}
\hline 4 & A & B & C & D & $\mathrm{E}$ & $\mathrm{F}$ & G & $\mathrm{H}$ & 1 & J & $\mathrm{k}$ \\
\hline 1 & \multicolumn{11}{|c|}{ ASSIGNMENT OF COURSES TO FACULTY REPORT } \\
\hline \multicolumn{12}{|l|}{2} \\
\hline 3 & & & & \multicolumn{3}{|c|}{ Quarterly WTU } & \begin{tabular}{|l|} 
AY Total \\
WTU
\end{tabular} & \multicolumn{3}{|c|}{ Quarterly Number of Sections } & $\begin{array}{l}\text { AY Number } \\
\text { of Sections }\end{array}$ \\
\hline 4 & Faculty & Course - Type & Pref & Fall 2010 & Winter 2011 & Spring 2011 & & Fall 2010 & Winter 2011 & Spring 2011 & \\
\hline 5 & Faculty 1 & IME 156 - Lab & 1 & & 4 & 4 & 8 & & 2 & 2 & 4 \\
\hline 6 & & IME 314 - Lec & 0 & 3 & & 3 & 6 & 1 & & 1 & 2 \\
\hline 7 & & IME 420 - Lab & 0 & 2 & 4 & & 6 & 1 & 2 & & 3 \\
\hline 8 & & IME 420 - Lec & 0 & 3 & 3 & & 6 & 1 & 1 & & 2 \\
\hline 9 & & IME 510 - Lec & 0 & 4 & & & 4 & 1 & & & 1 \\
\hline 10 & Faculty $1 \mathrm{~T}$ & & & 12 & 11 & 7 & 30 & 4 & 5 & 3 & 12 \\
\hline 11 & Faculty 2 & IME 301 - Act & 0 & 1.3 & 1.3 & & 2.6 & 1 & 1 & & 2 \\
\hline 12 & & IME 301 - Lec & 0 & 3 & 3 & & 6 & 1 & 1 & & 2 \\
\hline 13 & & IME 405 - Act & 0 & 1.3 & & & 1.3 & 1 & & & 1 \\
\hline 14 & & IME 405 - Lec & 0 & 3 & & & 3 & 1 & & & 1 \\
\hline 15 & & IME 457 - Lec & 0 & 2 & & & 2 & 1 & & & 1 \\
\hline 16 & & IME 481/482 - Lab & 0 & & & 2 & 2 & & & 1 & 1 \\
\hline 17 & & IME 541 - Lab & 0 & & 2 & & 2 & & 1 & & 1 \\
\hline 18 & & IME 541 - Lec & 0 & & 3 & & 3 & & 1 & & 1 \\
\hline 19 & & IME 545 - Lab & 0 & & & 2 & 2 & & & 1 & 1 \\
\hline 20 & & IME 545 - Lec & 0 & & & 3 & 3 & & & 1 & 1 \\
\hline 21 & Faculty $2 \mathrm{~T}$ & & & 10.6 & 9.3 & 7 & 26.9 & 5 & 4 & 3 & 12 \\
\hline
\end{tabular}

Figure 13: Assignment of Courses to Faculty Report 


\section{Scheduling}

\section{Overview}

The goal of the scheduling feature is to provide a Microsoft Excel and Solver based scheduling tool to the department scheduler to streamline the scheduling process and improve the schedule quality. As previously reviewed, the current schedule process is very laborious and prone to error due to the number of pieces that have to fit together just right. Because it is currently done manually, there is room for improvement. While the assignment is created for the entire academic year, the time table scheduling is typically only performed one term at a time since the schedules from one quarter to the next don't have any dependency on each other.

\section{Inputs and Constraints}

The major inputs and constraints to the scheduling dashboard are: faculty time availability and preference for the term, course assignment for each section offered, section constraints, default university schedule time patterns, course details, and course overlap constraints. Each of these inputs and constraints has been incorporated into the scheduling dashboard as input into the scheduling model formulation. For the most part, the scheduling dashboard is not the recommended input portal for the data, but instead a dashboard that pulls the data from other tables and consolidates it to display the data in the format required.

Faculty time availability and preferences is how the system understands when a faculty member can or cannot teach and what times are preferred over other times. This input uses the time preference scale of 1 to 4 as defined in Figure 14 and is based on faculty member input prior to planning and scheduling. 
Figure 14: Faculty Time Preference Key

The faculty availability preferences as shown in Figure 15 incorporates the available/not available feedback from the faculty as well as feedback around professional development days, and any time of day preference input provided. Each half hour of the week from $7 \mathrm{AM}$ to $10 \mathrm{PM}$ can have a different availability preference defined. For the scheduling dashboard, the data is displayed in a tabular format with each row representing a faculty member. For easy reference, each input is color coded to match the preference key.

\begin{tabular}{|c|c|c|c|c|c|c|c|c|c|c|c|c|c|c|c|c|c|c|c|c|c|c|c|c|}
\hline 4 & A & B & C & L & M & $\mathrm{N}$ & 0 & & $\mathrm{P}$ & $Q$ & $\mathrm{R}$ & S & T & U & V & W & $\mathrm{x}$ & Y & z & AA & $A B$ & $A C$ & $A D$ & A \\
\hline 1 & \multicolumn{24}{|c|}{ Faculty Availability Preferences } \\
\hline 2 & & & & M & M & M & M & & M & M & M & M & M & M & M & M & M & M & M & M & M & M & M & M \\
\hline 3 & & & & 7.0 & 7.5 & 8.1 & 8. & & 9.0 & 9.5 & 10.0 & 10.5 & 11.0 & 11.5 & 12.0 & 12.5 & 1.0 & 1.5 & 2.0 & 2.5 & 3.0 & 3.5 & 4.0 & $\overline{4}$ \\
\hline 4 & $\mathbf{K}$ & \begin{tabular}{|c|} 
Faculty \\
Name
\end{tabular} & $\begin{array}{c}\text { Faculty } \\
\text { Type }\end{array}$ & 7.0 & 7.5 & 8.1 & 8. & & 9.0 & 9.5 & 10.0 & 10.5 & 11.0 & 11.5 & 12.0 & 12.5 & 13.0 & 13.5 & 14.0 & 14.5 & 15.0 & 15.5 & 16.0 & 16 \\
\hline 5 & 1 & Staff & Staff & 2.5 & 2.5 & & 2 & 2 & 2 & 2 & 2 & 2 & 2 & 2 & 2 & 2 & 2 & 2 & 2 & 2 & 2 & 2 & 2 & \\
\hline 6 & 2 & Faculty 1 & Tenure/ $\pi$ & 4 & 2 & t & 4 & 4 & 3 & 2 & 2 & 2 & 柾 & - & 3 & 3 & , & 2 & 7 & 2 & 2 & 2 & 2 & \\
\hline 7 & 3 & Faculty 2 & Tenure/ $\pi$ & 4 & 2 & t & 4 & 4 & 3 & 3 & 3 & 3 & 3 & 3 & 3 & 3 & 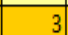 & 3 & 7 & 3 & 3 & 3 & 3 & \\
\hline 8 & 4 & Faculty 3 & Tenure/T & 4 & 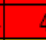 & 4 & 4 & 4 & 3 & 3 & 3 & 3 & 3 & 3 & 3 & 3 & $\rightarrow$ & 3 & 7 & 3 & 4 & 4 & 4 & \\
\hline 9 & 5 & Faculty 4 & Tenure/ $\pi$ & 3 & 3 & 3 & 3 & 3 & 3 & 3 & 2 & 2 & 2 & 2 & 2 & 2 & 2 & 2 & 2 & 2 & 2 & 2 & 2 & 2 \\
\hline 10 & 6 & Faculty 5 & Tenure/ $\pi$ & 4 & 2 & + & 2 & 2 & 1 & 1 & 1 & 1 & 1 & 1 & 3 & 3 & 1 & 1 & 1 & 1 & 1 & 1 & 1 & \\
\hline 11 & 7 & Faculty 6 & FERP & 3 & 3 & 3 & 3 & 3 & 3 & 3 & 2 & 2 & 2 & 2 & 2 & 2 & 2 & 2 & 2 & 2 & 2 & 2 & 2 & 2 \\
\hline 12 & 8 & Faculty 7 & Tenure/TT & 2.5 & 2.5 & & 2 & 2 & 2 & 2 & 2 & 2 & 2 & 2 & 2 & 2 & 2 & 2 & 2 & 2 & 2 & 2 & 2 & \\
\hline 13 & 9 & Faculty 8 & Tenure/ $\pi$ & 3 & 3 & 3 & 3 & 3 & 3 & 3 & 3 & 3 & 3 & 3 & 2 & 2 & 2 & 2 & 7 & 2 & 2 & 2 & 2 & \\
\hline 14 & 10 & Faculty 9 & Tenure/ $\pi$ & 2 & 2 & & 2 & 2 & 2 & 2 & 2 & 2 & 7 & 2 & 2 & 2 & 7 & 2 & T & 2 & 2 & 2 & 2 & \\
\hline 15 & 11 & Faculty 10 & Tenure/T & 3 & 3 & & 3 & 3 & 2 & 2 & 2 & 2 & 2 & 2 & 2 & 2 & 2 & 2 & 2 & 2 & 2 & 2 & 2 & \\
\hline 16 & 12 & Faculty 11 & Tenure/ $\pi$ & 3 & 3 & 3 & 3 & 3 & 2.5 & 2.5 & 2.5 & 2.5 & 2.5 & 2.5 & 2.5 & 2.5 & 2.5 & 2.5 & 2.5 & 2.5 & 2.5 & 2.5 & 2.5 & \\
\hline 17 & 13 & Faculty 12 & FERP & 2 & 2 & 2 & 2 & 2 & 2 & 2 & 2 & 2 & 2 & 2 & 2 & 2 & 2 & 2 & 2 & 2 & 2 & 2 & 2 & \\
\hline 18 & 14 & Faculty 13 & Tenure/ $\pi$ & 3 & 3 & 3 & 3 & 3 & 3 & 3 & 2 & 2 & 2 & 2 & 2 & 2 & 2 & 2 & 2 & 2 & 2 & 2 & 2 & \\
\hline 19 & 15 & Faculty 14 & Lecturer & 3 & 3 & 3 & 3 & 3 & 3 & 3 & 3 & 3 & 3 & 3 & 2 & 2 & 2 & 2 & 2 & 2 & 2 & 2 & 2 & \\
\hline 20 & 16 & Faculty 15 & Lecturer & 2 & 2 & 2 & & 2 & 2 & 2 & 2 & 2 & 2 & 2 & 2 & 2 & 2 & 2 & 2 & 2 & 2 & 2 & 2 & \\
\hline
\end{tabular}

Figure 15: Faculty Availability Preferences 
Course and section assignment is an output of the assignment dashboard and an input to the scheduling dashboard. The assignment needs to detail out by section each faculty member assigned to the section.

\begin{tabular}{|c|c|c|c|c|c|c|}
\hline \multirow{2}{*}{$\begin{array}{l}517 \\
518\end{array}$} & \multicolumn{4}{|c|}{ Conrst_Facaltp Arailabilit } & \multicolumn{2}{|c|}{ Accpersble Threshold } \\
\hline & & & & & & \\
\hline 519 & J & $\begin{array}{c}\text { Conrse } \\
\text { Trpe }\end{array}$ & Trpe & Section & $\begin{array}{l}\text { Facalty } \\
\text { Assigeed }\end{array}$ & $\begin{array}{c}\text { Howrs } \\
\text { Per } \\
\text { Petret }\end{array}$ \\
\hline 542 & 23 & IFIE 143 - Lab & $1 \mathrm{LAB}$ & 1 & STAFF 100 & 3 \\
\hline 543 & 24 & IPME 143 - Lab & $1 \mathrm{LAB}$ & 2 & STAFF 100 & 3 \\
\hline 544 & 25 & IFIE 143 - Lab & $1 \mathrm{LAB}$ & 3 & STAFF 100 & 3 \\
\hline 545 & 26 & IFVE 143 - Lab & $1 \mathrm{LAB}$ & 4 & STAFF 100 & 3 \\
\hline 546 & 27 & IFVE 143 - Lab & $1 \mathrm{LAB}$ & 5 & STAFF 100 & 3 \\
\hline 547 & 28 & IFIE 143 - Lab & $1 \mathrm{LAB}$ & 6 & STAFF 100 & 3 \\
\hline 548 & 29 & IPME 143 - Lec & $1 \mathrm{LEC}$ & 1 & STAFF 100 & 1 \\
\hline 549 & 30 & IPME 144 - Lab & 2 LAB & 1 & STAFF 100 & 6 \\
\hline 550 & 31 & IMIE 144 - Lab & 2 LAB & 2 & STAFF 100 & 6 \\
\hline 551 & 32 & IFIE 144 - Lob & 2 LAB & 3 & STAFF 100 & 6 \\
\hline 552 & 33 & IFIE 144 - Lob & $2 \mathrm{LAB}$ & 4 & STAFF 100 & 6 \\
\hline 553 & 34 & IMIE 144 - Lec & 2 LEC & 1 & STAFF 100 & 2 \\
\hline 554 & 35 & IPVE 156 - Lab & $1 \mathrm{LAB}$ & 1 & STAFF 100 & 3 \\
\hline 555 & 36 & IFVE 156 - Lab & $1 \mathrm{LAB}$ & 2 & STAFF 100 & 3 \\
\hline 556 & 37 & IPVE 156 - Lab & $1 \mathrm{LAB}$ & 3 & STAFF 100 & 3 \\
\hline 557 & 38 & IMVE 156 - Lab & $1 \mathrm{LAB}$ & 4 & STAFF 100 & 3 \\
\hline$\cdots$ & $\cdots$ & $\ldots-\cdots$ & $\cdots \cdots$ & - & $-\cdots$ & 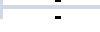 \\
\hline
\end{tabular}

Figure 16: Course and Section Assignment

Section availability and constraints are introduced after the section assignment is integrated with the faculty availability preferences. The result of the section assignments merging with the faculty availability preference is an availability preference for each section offered as seen in Figure 17. Any external section constraints alter the preferences of the section availability. For example, if 300 level courses should not conflict with Stat 321 then the time when Stat 321 is offered needs to be marked as unavailable time in the section constraints. 


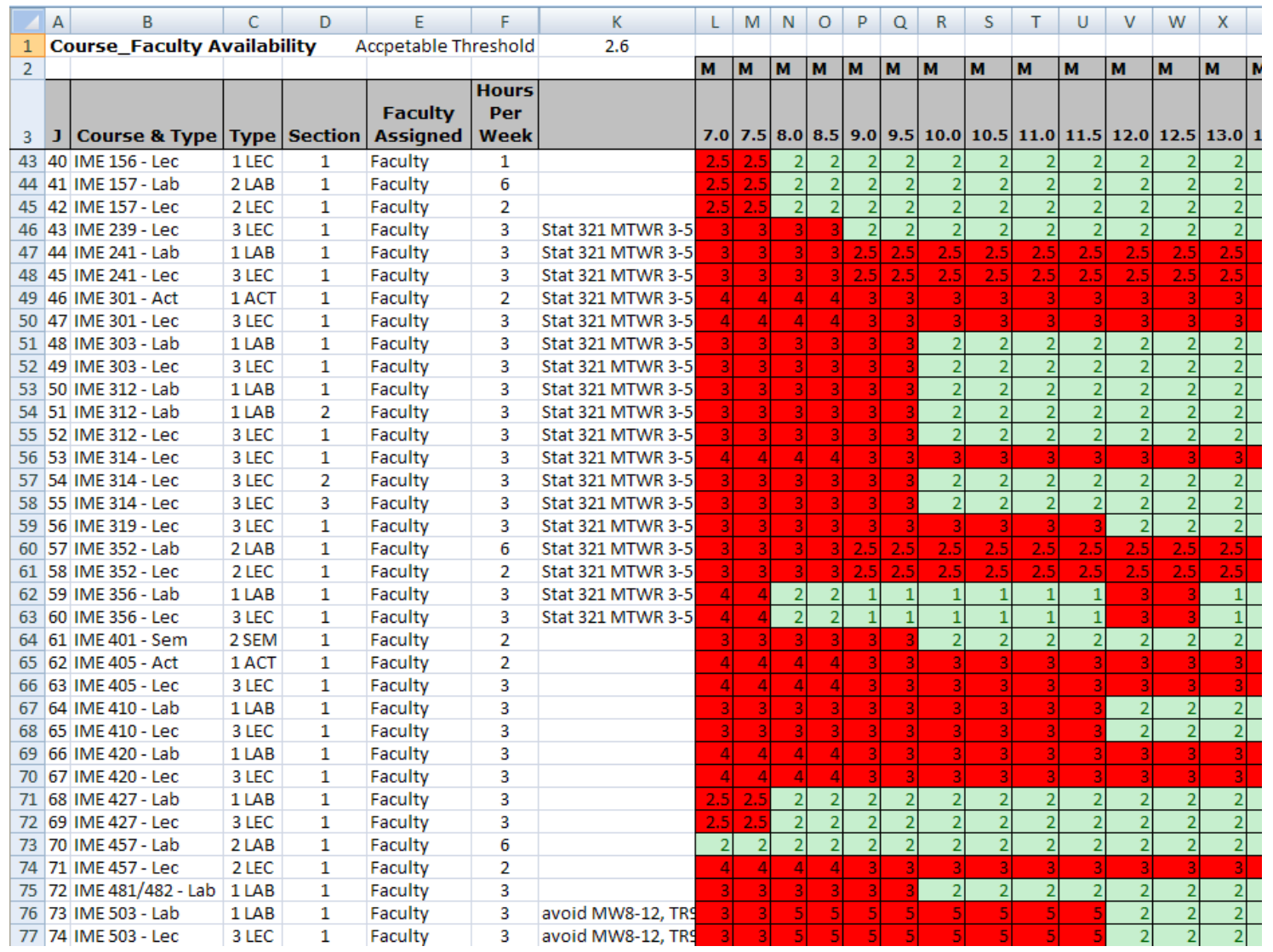

Figure 17: Section Availability and Constraints

The preference acceptable threshold is a model input control that was introduced to minimize the problem size. If a preference value is less than or equal to the acceptable threshold it is considered as an option. If the preference value for the half hour time slot is above the acceptable threshold, the time is considered unavailable. This input allows the user to control the model and not schedule anything in preference category 3 unless there is no other alternative. This input can be lessened or tightened depending on the model output. For the fall schedule, an acceptable threshold of 2.6 was used.

University schedule time patterns are the default times slots as seen if Figure 18 that the university prefers to have courses scheduled in order to maximize efficiency of 
room and minimize overlap of courses during peak hours. Outside peak hours the departments have more flexibility to create additional timeslots. The default time slots must be inputted into the tool along with any custom time slots that the department uses. These time patterns are inputted using the same half hourly format as the remaining time based inputs in the scheduling dashboard as seen in Figure 19. Each half hour during the week is marked with a binary indicator where 0 means the time is not active and 1 means it is an active meeting time for the defined time slot.

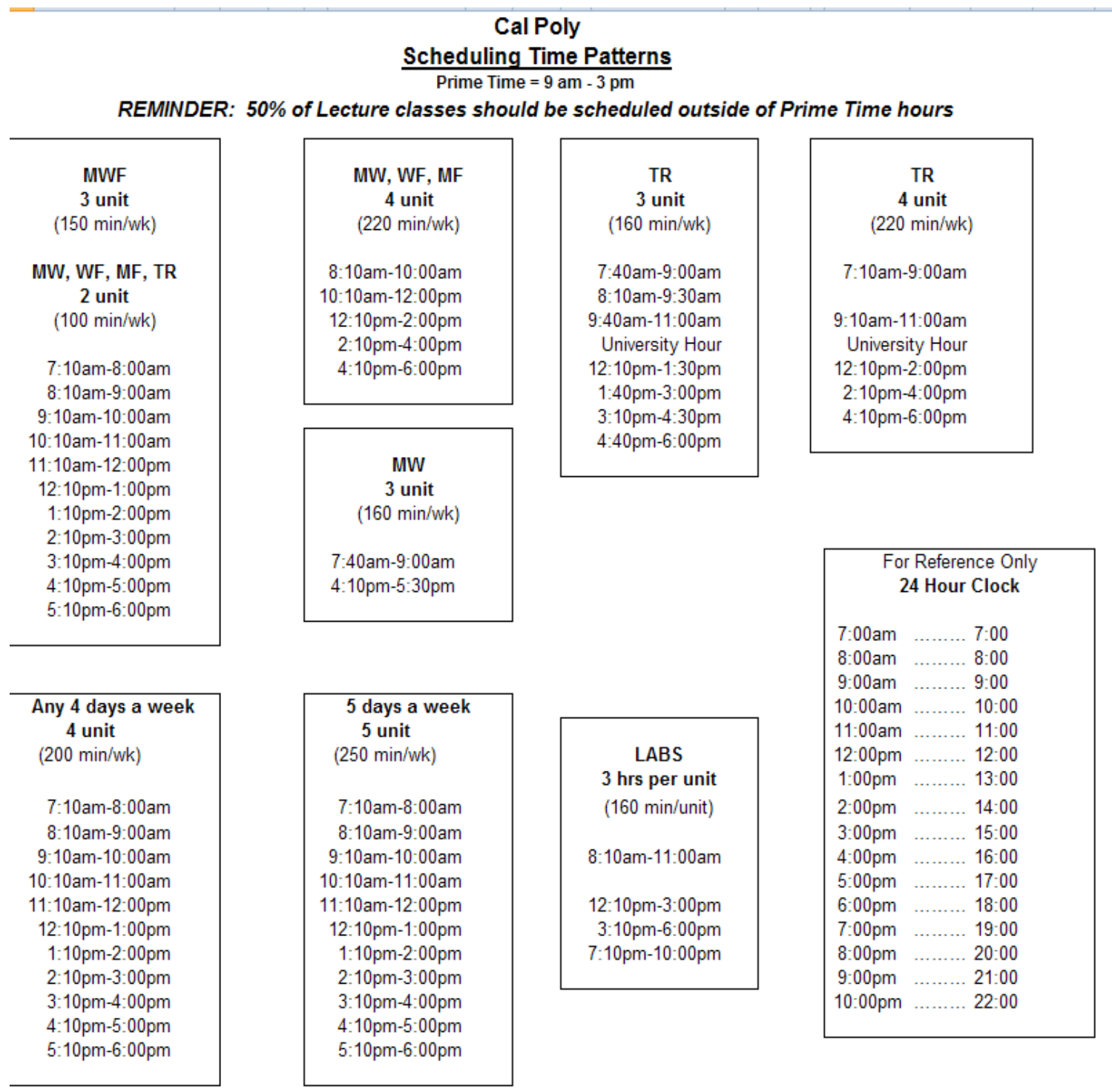

Figure 18: University Schedule Time Patterns 


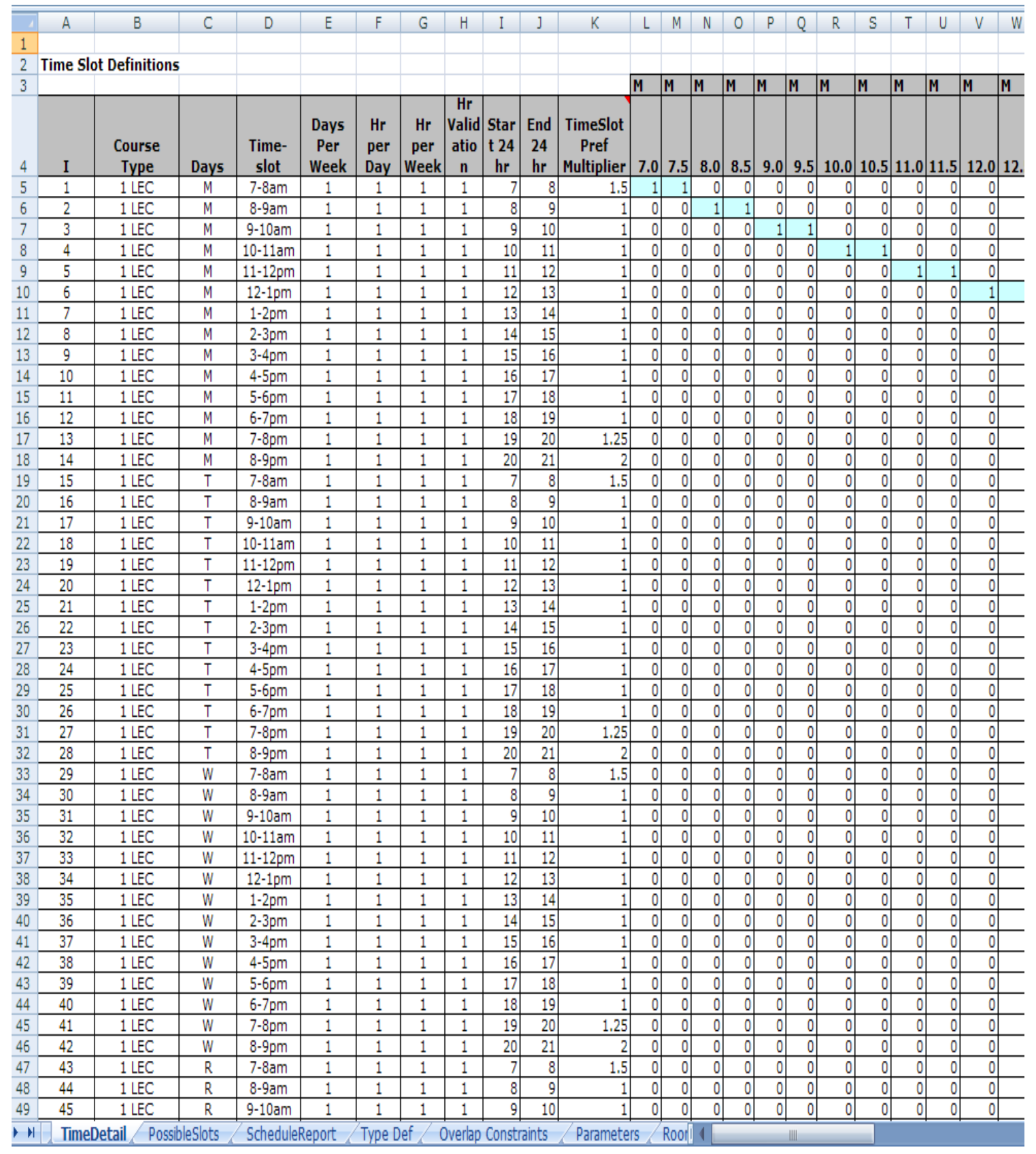

Figure 19: Time Slot Definitions

Time slot preference is a model input that incorporates student and department preferences into the scheduling process. The time slot preference is used as a multiplier applied to the section availability preference. This allows for preferences outside the 
faculty preferences to impact the schedule outcome. The general preference pattern applied for fall scheduling is as follows:

- 0.95 for $1.5 \mathrm{hr} 3$ unit lectures or $2 \mathrm{hr} 4$ unit lectures

- 1.5 for start before 8 or after 8

- 1.25 end after 5 on Friday

- 1.5 for start after 5 on Friday

- 2 for start Friday after 7

Course details include any room requirements, course type and unit definition. The room requirements as seen in Figure 20 are required to avoid conflicts in the department labs. The course type and unit definition are required in order to link the course to appropriate time slots. 


\begin{tabular}{|c|c|c|c|c|c|c|c|c|}
\hline \multicolumn{9}{|l|}{4} \\
\hline 5 & Course \& Type & $\nabla$ & Component & $\nabla$ & Location & $\nabla$ & $\begin{array}{l}\text { Alternate } \\
\text { Location }\end{array}$ & $\nabla$ \\
\hline 6 & IME 101 - Lab & & $1 \mathrm{LAB}$ & & $192-0220$ & & & \\
\hline 7 & IME 130 - Lec & & 1 LEC & & ANY & & & \\
\hline 8 & IME 130 - Lab & & $1 \mathrm{LAB}$ & & $192-0220$ & & & \\
\hline 9 & IME 140 - Lec & & 1 LEC & & ANY & & & \\
\hline 10 & IME 140 - Lab & & 1 LAB & & ANY & & & \\
\hline 11 & IME 141 - Lab & & $1 \mathrm{LAB}$ & & $041-0103$ & & & \\
\hline 12 & IME 142 - Lec & & 1 LEC & & ANY & & & \\
\hline 13 & IME 142 - Lab & & $1 \mathrm{LAB}$ & & $041-0103$ & & & \\
\hline 14 & IME 143 - Lec & & 1 LEC & & ANY & & & \\
\hline 15 & IME 143 - Lab & & $1 \mathrm{LAB}$ & & 041-0109 & & & \\
\hline 16 & IME 144 - Lec & & 2 LEC & & ANY & & & \\
\hline 17 & IME 144 - Lab & & 2 LAB & & 041-0109 & & & \\
\hline 18 & IME 156 - Lec & & 1 LEC & & ANY & & & \\
\hline 19 & IME 156 - Lab & & 1 LAB & & $192-0105$ & & & \\
\hline 20 & IME 157 - Lec & & 2 LEC & & ANY & & & \\
\hline 21 & IME 157 - Lab & & 2 LAB & & $192-0105$ & & & \\
\hline 22 & IME 200 - Ind & & IND & & ANY & & & \\
\hline 23 & IME 223 - Lec & & 3 LEC & & ANY & & & \\
\hline 24 & IME 223 - Lab & & 1 LAB & & $192-0221$ & & & \\
\hline 25 & IME 239 - Lec & & 3 LEC & & ANY & & & \\
\hline 26 & IME 240 - Ind & & IND & & ANY & & & \\
\hline 27 & IME 241 - Lec & & 3 LEC & & ANY & & & \\
\hline 28 & IME 241 - Lab & & 1 LAB & & 041-0109 & & & \\
\hline 29 & IME 251 - Lec & & 2 LEC & & ANY & & & \\
\hline 30 & IME 251 - Lab & & 2 LAB & & & & & \\
\hline 21 & TMAC $2 n 1-1 \cap n$ & & $21 \mathrm{Cr}$ & & ANIV & & & \\
\hline
\end{tabular}

Figure 20: Room Requirements

Course conflict zones allow the user to define the courses that cannot overlap. The current model setup has 8 conflict zones setup which are defined as: 100 level lecture, 200 level, 300 level, 400 level, 500 level, manufacturing, 400 and 500 levels, and 300 and 400 level IE courses. By defining these course conflict zones it will minimize conflict between IME courses and allow students to take the courses they want and graduate quicker. The first pass of the schedule should be run with all the constraints in place, however if the model is over constrained and there is not feasible solution, then these constraints can be refined or loosened. The course conflict input worksheet as seen in Figure 21 summarizes the total weekly hours for each conflict area 
and each defined room. In order to schedule the number of planned sections in a manner that doesn't overlap, the required hours are needed per week. So if there are 50 required hours, you cannot expect all the courses to fit between 8 to 5 during the week. In order to schedule the courses without conflict the schedule will include courses placed outside the peak time.

\begin{tabular}{|c|c|c|c|c|c|c|c|c|c|c|}
\hline 4 & A & C & D & $E$ & $\mathrm{H}$ & I & J & K & L & \\
\hline 2 & & & & & & & & & & \\
\hline 3 & & & & & Room & $\begin{array}{l}\text { Required Hours } \\
\text { per Week }\end{array}$ & & & & \\
\hline 4 & & & & & 041-0103 & 39 & & & & \\
\hline 5 & & & & & 041-0109 & 51 & & & & \\
\hline 6 & & & & & \begin{tabular}{|l|}
$192-0105$ \\
\end{tabular} & 27 & & & & \\
\hline 7 & & & & & \begin{tabular}{|l|}
$192-0220$ \\
\end{tabular} & 15 & & & & \\
\hline 8 & & & & & 192-0221 & 28 & & & & \\
\hline 9 & & & & & & & & & & \\
\hline 10 & & & Requirec & d Hours pe & r Week: & 26 & 9 & 40 & 36 & \\
\hline 11 & & & & & & & & & & \\
\hline 12 & & & & & & 100 level Lec & 200 level & 300 level & 400 level & 5001 \\
\hline 13 & Course \& Type & Req by IE & Req by Mfd & Sec Req & Room & Conflict Zone 1 & Conflict Zone 2 & \begin{tabular}{|l|} 
Conflict Zone 3 \\
\end{tabular} & Conflict Zone 4 & Conf \\
\hline 14 & IME 101 - Lab & $x$ & $\mathrm{x}$ & 2 & 192-0220 & 1 & & & & \\
\hline 15 & IME 130 - Lab & 0 & 0 & 2 & $192-0220$ & & & & & \\
\hline 16 & IME 130 - Lec & 0 & 0 & 1 & ANY & & & & & \\
\hline 17 & IME 140 - Lab & $x$ & $x$ & 2 & ANY & 1 & & & & \\
\hline 18 & IME 140 - Lec & $\mathrm{x}$ & $x$ & 1 & ANY & 1 & & & & \\
\hline 19 & IME 141 - Lab & $\mathrm{X}$ & $x$ & 5 & 041-0103 & & & & & \\
\hline 20 & IME 142 - Lab & 0 & $x$ & 8 & 041-0103 & & & & & \\
\hline 21 & IME 142 - Lec & 0 & $\mathrm{x}$ & 1 & ANY & 1 & & & & \\
\hline 22 & IME 143 - Lab & 0 & 0 & 6 & 041-0109 & & & & & \\
\hline 23 & IME 143 - Lec & 0 & 0 & 1 & ANY & 1 & & & & \\
\hline 24 & IME 144 - Lab & $\mathrm{x}$ & $x$ & 4 & 041-0109 & & & & & \\
\hline 25 & IME 144 - Lec & $\mathrm{x}$ & $x$ & 1 & ANY & 1 & & & & \\
\hline 26 & IME 156 - Lab & 57. Req fo & 0 & 5 & 192-0105 & & & & & \\
\hline 27 & IME 156 - Lec & 57. Req fo & 0 & 1 & ANY & 1 & & & & \\
\hline 28 & IME 157 - Lab & $X-$ or 156 & $x$ & 1 & 192-0105 & 1 & & & & \\
\hline 29 & IME 157 - Lec & $X-$ or 156 & $x$ & 1 & ANY & 1 & & & & \\
\hline 30 & IME 223 - Lab & $x$ & $x$ & 0 & 192-0221 & & 1 & 1 & & \\
\hline 31 & IME 223 - Lec & $\mathrm{x}$ & $x$ & 0 & ANY & & 1 & 1 & & \\
\hline 32 & IME 239 - LeC & $x$ & 0 & 1 & ANY & & 1 & 1 & & \\
\hline 33 & IME 241 - Lab & 0 & $\mathrm{x}$ & 1 & 041-0109 & & 1 & 1 & & \\
\hline 34 & IME 241 - Lec & 0 & $\mathrm{x}$ & 1 & ANY & & 1 & 1 & & \\
\hline 35 & IME 301 - Act & $x$ & 0 & 1 & 192-0221 & & & 1 & & \\
\hline 36 & IME 301 - Lec & $x$ & 0 & 1 & ANY & & & 1 & & \\
\hline 37 & IME 303 - Lab & $\mathrm{x}$ & 0 & 1 & 192-0221 & & & 1 & & \\
\hline 38 & IME 303 - Lec & $x$ & 0 & 1 & ANY & & & 1 & & \\
\hline 39 & IME 312 - Lab & $\mathrm{x}$ & 0 & 2 & 192-0221 & & & 1 & & \\
\hline 40 & IME 312 - Lec & $x$ & 0 & 1 & ANY & & & 1 & & \\
\hline$\Delta 1$ & TME $211.1 \mathrm{Im}$ & $\mathrm{v}$ & $\mathrm{v}$ & 2 & AMIV & & & 1 & & \\
\hline
\end{tabular}

Figure 21: Course Conflict Constraints 


\section{Objective and Approach}

The goal of the scheduling model formulation is to schedule each section to a feasible time slot that doesn't conflict with other time slots assigned to the same faculty member, same room, or same conflict zone while minimizing preference values in order to generate a schedule that is desirable. This is performed using an LP engine included in Solver.

Prior to running the model, the data requires some complex setup. Transforming and setting up the model in a flexible interface that can be solved using solver was one of the challenges of this system.

Once all the inputs are defined, a list of possible time slots for each section is generated as seen in Figure 22. The faculty member must be available with a preference value under the preference threshold for each half hour period in the timeslot. If a faculty member is unavailable for any portion of the timeslot, it is not a valid timeslot option. 


\begin{tabular}{|c|c|c|c|c|c|c|c|c|c|c|c|c|c|c|}
\hline $\begin{array}{c}\text { Assign } \\
\text { to } \\
\text { Timeslo } \\
t \\
\end{array}$ & \begin{tabular}{|c|} 
Num \\
Slots \\
assigne \\
d to \\
course \\
\end{tabular} & $\begin{array}{l}\text { Course } \\
\text { Section }\end{array}$ & J & $\mathbf{I}$ & $\begin{array}{c}\text { Faculty } \\
\text { Pref }\end{array}$ & $\begin{array}{c}\text { Timeslo } \\
\text { t Pref } \\
\text { Multipli } \\
\text { er }\end{array}$ & \begin{tabular}{|c} 
Faculty \\
Assigned
\end{tabular} & $\begin{array}{l}\text { Require } \\
\text { d Room }\end{array}$ & $\begin{array}{c}\text { Course } \\
\text { Type }\end{array}$ & Days & $\begin{array}{c}\text { Time- } \\
\text { slot }\end{array}$ & $\begin{array}{c}\text { Days } \\
\text { Per } \\
\text { Week }\end{array}$ & $\begin{array}{c}\text { Hr per } \\
\text { Day }\end{array}$ & $\begin{array}{c}\text { Hr per } \\
\text { Week }\end{array}$ \\
\hline 0 & 1 & IME 101 - Lab-1 & 1 & 70 & 2 & 1 & Faculty 1 & $192-0220$ & $1 \mathrm{LAB}$ & $\mathrm{M}$ & 9-12pm & 1 & 3 & 3 \\
\hline 0 & 1 & IME 101 - Lab-1 & 1 & 71 & 2 & 1 & Faculty 1 & $192-0220$ & $1 \mathrm{LAB}$ & $\mathrm{M}$ & $12-3 \mathrm{pm}$ & 1 & 3 & 3 \\
\hline 0 & 1 & IME 101 - Lab-1 & 1 & 77 & 2 & 1 & Faculty 1 & $192-0220$ & $1 \mathrm{LAB}$ & $T$ & $12-3 \mathrm{pm}$ & 1 & 3 & 3 \\
\hline 0 & 1 & IME 101 - Lab-1 & 1 & 82 & 2 & 1 & Faculty 1 & $192-0220$ & $1 \mathrm{LAB}$ & W & 9-12pm & 1 & 3 & 3 \\
\hline 0 & 1 & IME 101 - Lab-1 & 1 & 83 & 2 & 1 & Faculty 1 & $192-0220$ & $1 \mathrm{LAB}$ & W & 12-3pm & 1 & 3 & 3 \\
\hline 0 & 1 & IME 101 - Lab-1 & 1 & 89 & 2 & 1 & Faculty 1 & $192-0220$ & $1 \mathrm{LAB}$ & $R$ & $12-3 p m$ & 1 & 3 & 3 \\
\hline 1 & 1 & IME 101 - Lab-1 & 1 & 94 & 2 & 1 & Faculty 1 & $192-0220$ & $1 \mathrm{LAB}$ & $\mathrm{F}$ & 9-12pm & 1 & 3 & 3 \\
\hline 0 & 1 & IME 101 - Lab-1 & 1 & 95 & 2 & 1 & Faculty 1 & $192-0220$ & $1 \mathrm{LAB}$ & $\mathrm{F}$ & $12-3 p m$ & 1 & 3 & 3 \\
\hline 0 & 1 & IME 101 - Lab-2 & 2 & 70 & 2 & 1 & Faculty 1 & $192-0220$ & $1 \angle A B$ & $\mathrm{M}$ & 9-12pm & 1 & 3 & 3 \\
\hline 1 & 1 & IME 101 - Lab-2 & 2 & 71 & 2 & 1 & Faculty 1 & $192-0220$ & $1 \mathrm{LAB}$ & $\mathrm{M}$ & 12-3pm & 1 & 3 & 3 \\
\hline 0 & 1 & IME 101 - Lab-2 & 2 & 77 & 2 & 1 & Faculty 1 & $192-0220$ & $1 \mathrm{LAB}$ & $T$ & $12-3 p m$ & 1 & 3 & 3 \\
\hline 0 & 1 & IME 101 - Lab-2 & 2 & 82 & 2 & 1 & Faculty 1 & $192-0220$ & $1 \mathrm{LAB}$ & w & 9-12pm & 1 & 3 & 3 \\
\hline 0 & 1 & IME 101 - Lab-2 & 2 & 83 & 2 & 1 & Faculty 1 & $192-0220$ & $1 \mathrm{LAB}$ & W & $12-3 \mathrm{pm}$ & 1 & 3 & 3 \\
\hline 0 & 1 & IME 101 - Lab-2 & 2 & 89 & 2 & 1 & Faculty 1 & $192-0220$ & $1 \mathrm{LAB}$ & $R$ & 12-3pm & 1 & 3 & $\frac{3}{3}$ \\
\hline 0 & 1 & IME 101 - Lab-2 & 2 & 94 & 2 & 1 & Faculty 1 & $192-0220$ & $1 \mathrm{LAB}$ & $\mathrm{F}$ & $9-12 p m$ & 1 & 3 & 3 \\
\hline 0 & 1 & IME 101 - Lab-2 & 2 & 95 & 2 & 1 & Faculty 1 & $192-0220$ & 1 LAB & $\mathrm{F}$ & $12-3 p m$ & 1 & 3 & 3 \\
\hline 1 & 1 & IME 130 - Lab-1 & 3 & 69 & 2 & 1 & STAFF 100 & $192-0220$ & $1 \mathrm{LAB}$ & $\mathrm{M}$ & 8-11am & 1 & 3 & 3 \\
\hline 0 & 1 & IME 130 - Lab-1 & 3 & 70 & 2 & 1 & STAFF 100 & $192-0220$ & $1 \mathrm{LAB}$ & $\mathrm{M}$ & 9-12pm & 1 & 3 & 3 \\
\hline 0 & 1 & IME 130 - Lab-1 & 3 & 71 & 2 & 1 & STAFF 100 & $192-0220$ & $1 \mathrm{LAB}$ & $\mathrm{M}$ & $12-3 p m$ & 1 & 3 & 3 \\
\hline 0 & 1 & IME 130 - Lab-1 & 3 & 72 & 2 & 1 & STAFF 100 & $192-0220$ & $1 \mathrm{LAB}$ & $\mathrm{M}$ & 3-6pm & 1 & 3 & 3 \\
\hline 0 & 1 & IME 130 - Lab-1 & 3 & 73 & 2 & 1 & STAFF 100 & $192-0220$ & $1 \mathrm{LAB}$ & $\mathrm{M}$ & $6-9 \mathrm{pm}$ & 1 & 3 & 3 \\
\hline 0 & 1 & IME 130 - Lab-1 & 3 & 74 & 2.166667 & 1 & STAFF 100 & $192-0220$ & $1 \mathrm{LAB}$ & $\mathrm{M}$ & 7-10pm & 1 & 3 & 3 \\
\hline 0 & 1 & IME 130 - Lab-1 & 3 & 75 & 2 & 1 & STAFF 100 & $192-0220$ & $1 \mathrm{LAB}$ & $\mathrm{T}$ & 8-11am & 1 & 3 & $\frac{3}{3}$ \\
\hline 0 & 1 & IME 130 - Lab-1 & 3 & 76 & 2 & 1 & STAFF 100 & $192-0220$ & $1 \mathrm{LAB}$ & $\mathrm{T}$ & 9-12pm & 1 & 3 & 3 \\
\hline 0 & 1 & IME 130 - Lab-1 & 3 & 77 & 2 & 1 & STAFF 100 & $192-0220$ & $1 \mathrm{LAB}$ & $\mathrm{T}$ & $12-3 p m$ & 1 & 3 & 3 \\
\hline n & 1 & IIMAE $12 n$ _ I ah_1 & 21 & 78 & 2 & 1 & STAFE 1 (nก & 192_กววก & $11 \wedge R$ & TT & 2.6nm & 1 & 21 & $\sqrt{2}$ \\
\hline
\end{tabular}

Figure 22: Scheduling Dashboard - Feasible Timeslots

To avoid faculty member conflicts, a constraint for the maximum number of sections assigned to a faculty member in any given half hour period must be less than or equal to 1. Similarly, to avoid room conflicts, a constraint for the maximum number of sections assigned to a room in any given half hour period must be less than or equal to 1 .

Additionally, to avoid conflict zone member conflicts, a constraint for the maximum number of sections assigned to the conflict zone in any given half hour period must be less than or equal to 1. These constraints can be seen in Figure 23. 


\begin{tabular}{|c|c|c|c|}
\hline Conflict Area & Conflict Detail & Constratint & Max of Half Hours \\
\hline 100 level Lec & Conflict Zone 1 & $<=1$ & 1 \\
\hline 200 level & Conflict Zone 2 & $<=1$ & 1 \\
\hline 300 level & Conflict Zone 3 & $<=1$ & 1 \\
\hline 400 level & Conflict Zone 4 & $<=1$ & 1 \\
\hline 500 level & Conflict Zone 5 & $<=1$ & 1 \\
\hline Mfg & Conflict Zone 6 & $<=1$ & 1 \\
\hline 400 and 500 & Conflict Zone 7 & $<=1$ & 1 \\
\hline 300 and 400 Level IE & Conflict Zone 8 & $<=1$ & 1 \\
\hline \multirow{5}{*}{ Room } & 41-0103 & $<=1$ & 1 \\
\hline & 41-0109 & $<=1$ & 1 \\
\hline & 192-0105 & $<=1$ & 1 \\
\hline & 192-0220 & $<=1$ & 1 \\
\hline & 192-0221 & $<=1$ & 1 \\
\hline \multirow{13}{*}{ Faculty } & Faculty 1 & $<=1$ & 1 \\
\hline & Faculty 2 & $<=1$ & 1 \\
\hline & Faculty 3 & $<=1$ & 1 \\
\hline & Faculty 4 & $<=1$ & 1 \\
\hline & Faculty 5 & $<=1$ & 1 \\
\hline & Faculty 6 & $<=1$ & 1 \\
\hline & Faculty 7 & $<=1$ & 1 \\
\hline & Faculty 8 & $<=1$ & 1 \\
\hline & Faculty 9 & $<=1$ & 1 \\
\hline & Faculty 10 & $<=1$ & 0 \\
\hline & Faculty 11 & $<=1$ & 0 \\
\hline & Faculty 12 & $<=1$ & 1 \\
\hline & Faculty 13 & $<=1$ & 1 \\
\hline
\end{tabular}

Figure 23: Scheduling Dashboard - Conflict Constraints

For a feasible solution, each section must have one timeslot assigned.

\section{Model Definition}

Model Description

Scheduling is performed for only 1 quarter at a time so the dimension of quarter q has been eliminated from the formulation.

Notation Legend

$$
c=\text { course }
$$




$$
\begin{aligned}
& f=\text { faculty } \\
& s=\text { section } \\
& t=\text { timeslot } \\
& h=\text { half hour }(1 \text { to } 155) \\
& r=\text { room ( } 1 \text { to } 5) \\
& z=\text { course overlap zone (1 to } 8)
\end{aligned}
$$

\section{Data}

$\mathrm{c}_{\mathrm{st}}=$ faculty timeslot preference cost of assigning section $\mathrm{s}$ to timeslot $\mathrm{t}$

$$
\mathrm{p}_{\mathrm{st}}=\text { general timeslot preference cost of assigning section s to timeslot } \mathrm{t}
$$

\section{Variables}

$x_{s t}=1$ if section $\mathrm{s}$ is assigned to time-slot $t$

$$
0 \text { otherwise }
$$

$\mathrm{x}_{\mathrm{st}}<=\mathrm{y}_{\mathrm{sh}}$ for all $\mathrm{h}$ included in $\mathrm{t}$

$y_{s h}=1$ if sections $s$ is assigned to a timeslot that includes half hour $h$.

$$
0 \text { otherwise }
$$

where,

$$
\begin{aligned}
& s=1, \ldots, 100 \text { sections } \\
& t=1, \ldots, 500 \text { timeslots }
\end{aligned}
$$


$\{t(s)\}$ is the set of timeslots that are feasible for section s (e.g., duration and type of section matches duration and type of timeslot)

Objective

Minimize

$$
\sum_{s=1}^{100} \sum_{t=1}^{500} c_{s t} * p_{s t} * x_{s t}=\text { total preference cost of schedule }
$$

\section{Constraints}

- Timeslot assigned constraint - for each section one timeslot must be assigned.

$$
\sum_{\substack{s=1 \\ t(s)}}^{100} \sum_{t=1}^{500} x_{s t}=1
$$

- Room conflict constraint - for each half hour in each day, the number of sections assigned to each room must be less than or equal to 1 .

$\sum_{\substack{s=1 \\ s \in r}}^{100} y_{s h} \leq 1 \quad \forall h$ and $\forall r$

- Faculty member conflict constraint - for each half hour in each day, the number of sections assigned to each faculty member must be less than or equal to 1 .

$$
\sum_{\substack{s=1 \\ s \in f}}^{100} y_{s h} \leq 1 \quad \forall h \text { and } \forall f
$$


- Course overlap zone conflict constraint - for each half hour in each day, the number of sections assigned in each course overlap zone must be less than or equal to 1 .

$$
\sum_{\substack{s=1 \\ s \in z}}^{100} y_{s h} \leq 1 \quad \forall h \text { and } \forall z
$$

- Same day early and late constraint - for each faculty member for each day, if the number of sections assigned before $11 \mathrm{AM}$ is greater than 0 then the number of sections assigned after 6 PM must be 0 .

- Back to back late day and early day constraint - for each faculty member for each day, if the number of sections assigned after $6 \mathrm{PM}$ is greater than 0 then the number of sections assigned before 11 AM the next day must be 0 .

\section{Scheduling Output and Results}

The scheduling dashboard outputs a visual schedule for each course overlap conflict zone, room, and faculty member as seen in the example in Figure 24 . This visual schedule can be distributed to faculty members for their input. Additionally, a tabular format that can be used for data input into the university scheduling system is outputted. 


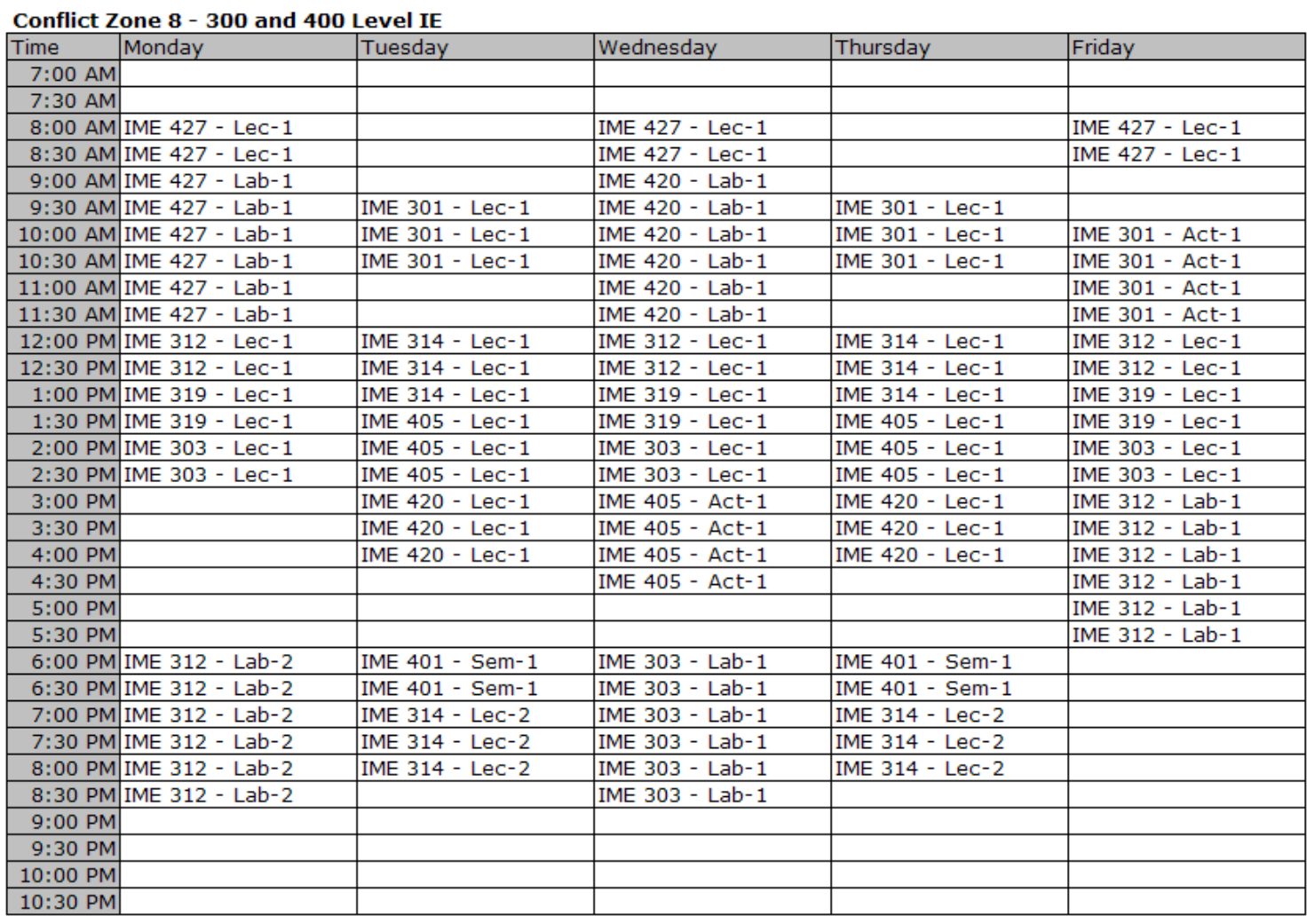

Figure 24: Example output schedule

With the final formulation as described above, the resulting schedule was very successful. Only a couple manual changes were done to avoid an afternoon lab on Friday and to accommodate a faculty member preference that was not properly defined in the input. Ideally, the inputs should have been modified and the schedule re-run since the manual changes created a schedule that did not obey the constraints defined. Additionally, due to machine setup constraints that are not currently defined in the scheduling system, some of the 100 level courses were manually scheduled.

During the experimentation process, there were many formulations evaluated and the model was fine tuned to the resulting formulation. Based on experimentation, additional constraints needed to be included to eliminate both early morning and late evening courses for the same faculty member as well as late evening followed by early 
morning the next day. The preference methodology was modified during the experimentation phase to include the time slot preference as a multiplier to the faculty member preference due to the flat nature of some faculty preferences. 


\section{Chapter 5: Revised Process}

\section{Course Assignment Process}

Demand

1. Determine courses that need to be offered each quarter taking into consideration
a. Previous year data
b. Curriculum
c. Flow chart
d. Published course offering chart
e. Pre requirements

f. Balanced student load - ensure that students at each class level don't have too many courses to take one quarter and not enough courses to take another quarter. This is particularly important for low demand programs.

g. WTU per course

h. Units per course

i. Required courses

j. Tech Elective courses

k. Required for other majors

I. Elective for other majors

m. Historic Co-op data

n. Budget

o. Balanced faculty load

2. Identify courses that need to be offered during the academic year, but the quarter the course is offered is flexible. Flag these as "Flexible" 
3. Determine appropriate number of student seats needed for each course (Demand) based on student population and historic data

4. Determine the number of lecture and lab sections to offer per each quarter based on
a. Total seats needed per year and per quarter
b. Flow chart
c. Appropriate lecture size
d. Appropriate lab size
e. Budget
f. WTU (if WTU varies based on class size)
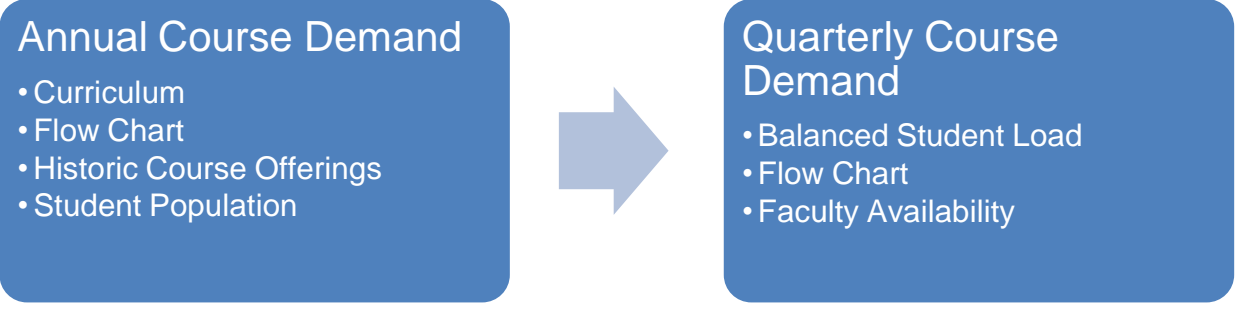

Figure 25: Course Demand Inputs

Supply

1. Determine target teaching load per quarter for Tenure and Tenure track faculty (Supply) taking into consideration
a. Contracted WTU
b. Committee work
c. Advising 
i. Senior project advising (0.25 WTU per student)

ii. Master student advising (0.5 WTU per student)

d. Assigned Time

i. Full cost

ii. University cost

e. Other

i. Other department teaching load

ii. Buy out

iii. Leave

iv. Leave w/o pay

v. Grad Coordinator

vi. Other
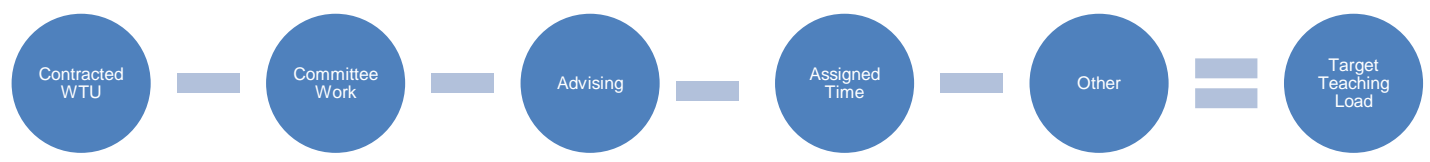

Figure 26: Target Teaching Load Calculation

2. Determine target teaching load per quarter for FERP faculty members taking into consideration

a. FERP contracted WTU

b. Requested FERP quarter off

c. Any adjustments to the contracted WTU for teaching load due to advising or other service

3. Determine faculty member flexibility for WTU assignment from quarter to quarter to determine maximum and minimum WTU per quarter (Quarterly WTU Tolerance) 
4. Determine department and faculty member flexibility for total WTU per year. Some faculty members might be willing to teach up to 2 extra WTU for the year to get an ideal schedule. The department might allow faculty members to teach fewer WTU than their target for the year for flexibility in scheduling. (Annual WTU Tolerance)

5. Evaluate lecturer funding and availability

Balance supply and demand

1. Ensure that the total demand and supply are balanced per quarter and for the year. If there is excess demand, determine if additional funding for lecturers is available.

Faculty Assignment Preferences

1. It is essential that the faculty preference matrix is up to date for each faculty member and their preferences are accurately recorded according to this scale:

\begin{tabular}{l|l|l}
\hline Category & Category Description & Category Example \\
\hline 0 & $\begin{array}{l}\text { Very strong interest in } \\
\text { teaching }\end{array}$ & $\begin{array}{l}\text { This is a course you are highly qualified } \\
\text { for and would really like to teach. }\end{array}$ \\
\hline 1 & Preferred course & qualified for and would like to instruct. \\
\hline 2 & $\begin{array}{l}\text { Acceptable course if } \\
\text { needed }\end{array}$ & $\begin{array}{l}\text { This isn't your highest priority course to } \\
\text { teach, but you are qualified and don't }\end{array}$ \\
\hline 3 or blank & Prefer not to teach & It would put strain on you, but you could \\
\hline 5 & $\begin{array}{l}\text { Very strong desire not to } \\
\text { teach course }\end{array}$ & $\begin{array}{l}\text { You would need to make special } \\
\text { arrangements to prepare for course, but }\end{array}$ \\
\hline 9 & $\begin{array}{l}\text { Absolutely not qualified } \\
\text { to teach course }\end{array}$ & $\begin{array}{l}\text { There is absolutely no way you can teach } \\
\text { this course }\end{array}$ \\
\hline
\end{tabular}

Figure 27: Faculty Course Preferences

2. Faculty preferences could potentially change from quarter to quarter or year to year depending on new preps. 
3. Identify any faculty members that don't have enough WTU in the acceptable or better categories based on the planned course offerings taking into consideration any overlap in faculty interests. Encourage these faculty members to identify additional interests.

Course Assignment

1. Review preference priority for Tenure/Tenure track, FERP, and Lecturers categories.

2. Prepare spreadsheet to run solver.

3. Setup transportation problem in solver if needed.

4. Allow solver to assign faculty to courses.

5. Review assignment and identify any undesirable assignments

6. Make adjustments as needed:

a. Adjust preference priority ranking between Tenure/TT faculty, FERP and Lecturers as needed.

b. Review possibility of modifying WTU tolerances to yield a more desirable schedule.

c. Consider splitting a Lec/Lab pair so that different faculty can be assigned to each section.

7. Rerun solver.

8. Review assignment and identify any undesirable assignments

9. Identify manual changes to the assignment that might resolve any undesirable assignments or make the schedule more equitable.

10. Create assignment report and review according to department policy. 


\section{Course Timetable Scheduling Process}

While it is preferable to take into consideration the entire academic year when assigning courses and if possible perform the course assignment at the same time, it is not important when creating the timetable. The timetable should be created one quarter at a time and is not dependent on other quarters.

University Time Table Slots

1. Update time slot definitions to reflect the university time slots and to include desired time slots that are acceptable but outside the university standard timeslots.

2. Each time slot is given a preference rating. This preference rating should be based on student and faculty preference of each time slot. For example, if it is preferable to not have

a. While the preference rating scale is relative, the scale that was used is as follows

i. Assigned a rating of 0.95 to highly preferred time slots. For example 3 unit lectures that occurred in two 80 minute class meetings during the week since this was a general preference in the department.

ii. A rating of 1 was used as a general or neutral rating.

iii. A rating of 1.25 was used for time slots on Friday that start after 3 but before 5 and late evening time slots that start after $7 \mathrm{pm}$ and before 8 pm.

iv. A rating of 1.5 was assigned to early morning time slots that start before 8 am. 
v. A rating of 2 was assigned to Friday evening time slots after 5 and lectures starting after 8 pm.

Faculty Availability and Timetable Preferences

1. Update faculty availability and timetable preferences by identifying each half hour during the week by using the following categories:

\begin{tabular}{l|l|l} 
Category & Category Name & \multicolumn{1}{c}{ Category Explanation } \\
\hline 1 & Preferred & $\begin{array}{l}\text { If there weren't any other constraints, these are the } \\
\text { hours you would like to teach. }\end{array}$ \\
\hline $\mathbf{2}$ or blank & Acceptable & Course scheduled any time in this range is \\
\hline 3 & Not preferred & $\begin{array}{l}\text { You would need to make special arrangements due } \\
\text { to previous commitments; will do it only if absolutely }\end{array}$ \\
\hline 4 or X & Unavailable & There is absolutelv no wav vou can teach durina this
\end{tabular}

Figure 28: Faculty Availability Preferences

2. In addition to the time of day preferences, understand each faculty preferences around desirable day and class format:
a. Are 50 minute lectures acceptable?
b. Are 80 or 110 minute lectures acceptable?
c. Professional development day?
d. Preferred maximum number of teaching days per week
e. Max hours per day
f. Are back to back courses acceptable?
g. Preferred maximum lectures hours per day
h. Preferred maximum lecture and lab hours per day

3. Ensure that each faculty member has enough acceptable or better hours to allow for some flexibility in timeslot assignment to avoid an over constrained system. 


\section{Course Time Preferences}

1. Determine if there are any time constraints for courses that will be offered. These constraints should be inputted in the same half hour format as the faculty time preferences. For example if a particular lab requires outdoor activities then it might not be feasible for it to take place during the evening lab time slot.

2. Adjust course time preferences for overlap constraints outside the department. For example Stat 321 should not overlap with any 300 level courses. Also, 500 level courses should not overlap with graduate business courses for the EMP program.

\section{Create Section-Faculty Availability Preferences}

1. For each section of a course that will be offered, the time preferences for the assigned faculty member are merged with the course time preferences to create the section preferences. In general these section preferences should not need any modification, however in rare cases or to manual force something they could be altered. The result of this is a half hourly matrix that shows if the preference for offering each section.

Create list of possible time slots for each section

1. Once the time constraints have been entered into the system, the next task is to identify each time slot that is a possibility for each section. This process takes into consideration the section-faculty availability preferences and the defined time slots. If the time slot works with the section-faculty availability with a preference above a defined preference threshold, then this time slot is considered as a 
potential option. If the timeslot overlaps with any non preferred half hours then the time slot is not a feasible option.

Course overlap constraints

1. While it is imperative that some courses don't overlap, too many course conflict constraints can quickly create an infeasible schedule, so the course overlap constraints need to be given some consideration and might need altering. Creating a schedule without overlap in courses that students might want to take during the same quarter, allows students to take the courses they need, when they want to take them in order to graduate sooner. In this model, the overlap constraints are setup as groups of courses that should not overlap. Each group name is general and can be customized with the specific courses that are included. The current groups are:

a. 100 level lecture or single section courses. Since some of the 100 level courses have multiple lab sections offered, but only 1 lectures section offered it is important that no 100 level lectures overlap. It is also important that a 100 level course with only one section offered should not overlap with other 100 level courses with a single section offered. This also applies to required major courses that have two sections offered. Since several of the 100 level offerings are service courses with lots of lab sections, it is ok that those labs overlap with each other in order to allow for a feasible schedule.

b. 200 level courses.

c. 300 level courses.

d. 400 level courses.

e. 500 level courses. 
f. Manufacturing courses.

g. 400 and 500 level courses.

h. 300 and 400 level Required IE courses.

2. Review the feasibility of the inputted overlap constraints. If 100 hours worth of course sections are defined as courses that cannot overlap, then this will create infeasibility. If the earliest reasonable time slot offered starts at 8 am and the latest reasonable time slot ends at $9 \mathrm{pm}$, then this only allows for 13 hours per day to schedule a set of courses that are not allowed to conflict. Taking into consideration that the university closes down by 5 on Friday and the Tuesday university hour, there are only 60 hours in the week to schedule sections without conflicts. The max available hours really comes down to fewer hours once you take into consideration the faculty availability constraints, room constraints, and some inefficiencies of scheduling courses. Ideally, there should be less than 50 hours in each conflict category.

3. Room course overlap constraints. If a course requires a particular lab, then this needs to be indicated in the required room column so that conflicts can be avoided. If a course does not need a particular room then "Any" should be indicated.

Schedule courses to timetable

1. Verify all the input data is inputted into the system properly

2. If needed, setup solver with the timetable transportation problem

3. Run solver

4. Review results

5. Create reports to allow for more visibility when reviewing results

6. Review results for each faculty member, room, and conflict avoidance group. 


\section{Chapter 6: Future enhancements}

While this methodology is many times better than the current process, there is still room for further enhancements. Potential enhancements can be categorized into the three stages (planning, assignment, and scheduling) of the overall process.

\section{Planning}

- Incorporate the curriculum flow chart to show the recommended quarter into planned course offerings for additional decision making power.

- Survey students to determine what courses they plan to take.

\section{Assignment}

- The assignment methodology does not take into consideration new preps for faculty members. An enhancement would include gathering, inputting, and building this into the assignment methodology. One piece of feedback from faculty is that the number of new preps should be equitable across faculty members.

\section{Scheduling}

- Incorporate machine setup constraints for 100 level lab scheduling. The scheduling methodology does not adequately schedule the 100 level labs due to some special rules that must be applied. Without the modification, 100 labs must be scheduled independently of the scheduling dashboard and the resulting schedule should be input into the system prior to scheduling the remaining courses.

- The university has a general rule that $50 \%$ of scheduled time must fall into off peak hours. This rule could be incorporated into the constraints. 
- The course overlap conflicts are defined using 8 zones. An optional enhancement would integrate a more detailed conflict matrix that allows the user to define conflicts for each course combination as seen in Figure 29. Potentially this matrix could allow for 3 levels of conflicts: conflicts that are not allowed, should be avoided, and are allowed.

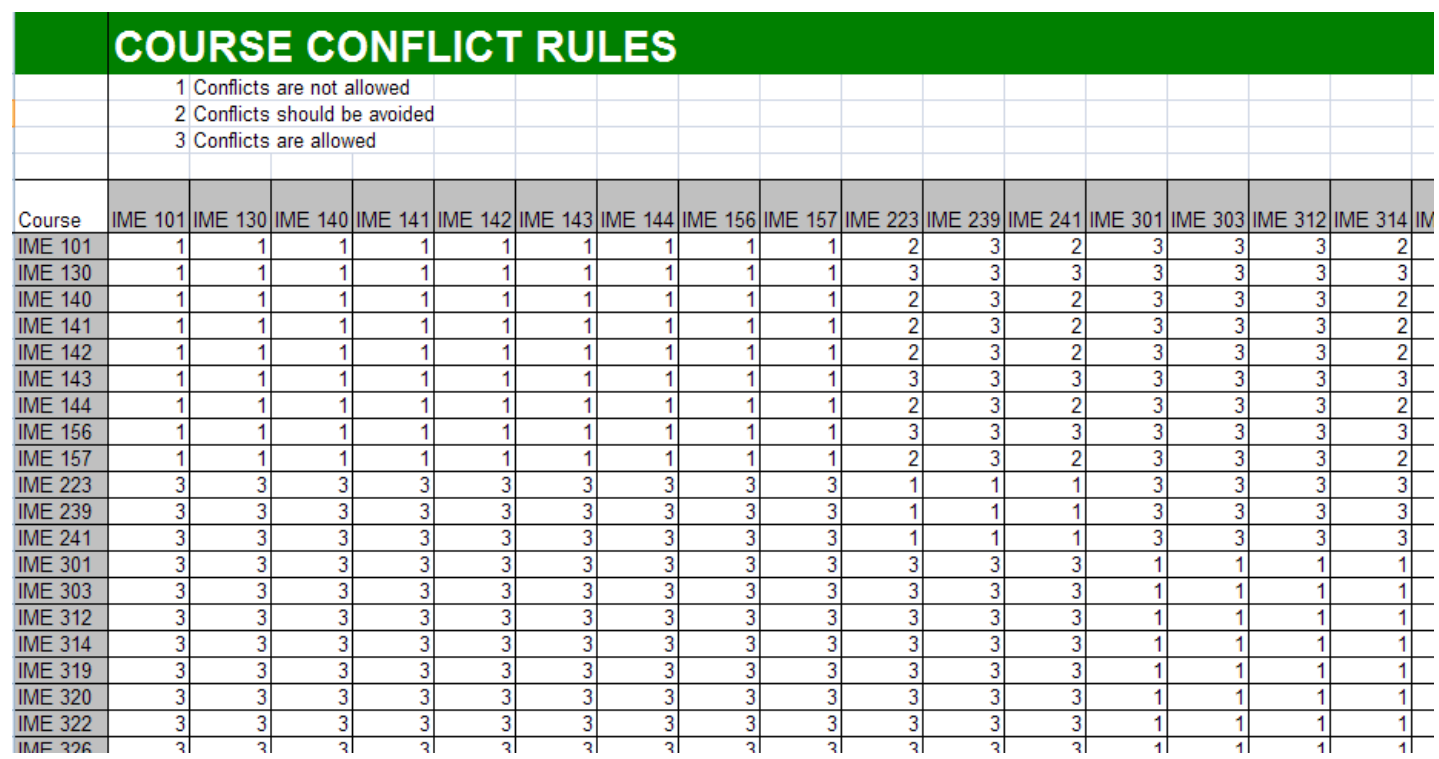

Figure 29: Proposed Course Conflict Matrix

\section{General}

- Enhancements to the links between assignment and scheduling dashboards would make the system as a whole more streamline and user friendly.

- Monitor the output and review for several quarters to determine optimality.

- As this system is implemented into the department scheduling process, the change will need to be managed to ensure the transition is smooth. 


\section{Chapter 7: Conclusion}

This solution has looked at the planning and scheduling process from end to end including the planning of course offerings, the assignment of faculty to courses, and the scheduling of courses to the timetable. By taking a systems approach and looking at the entire process, it allows the system to integrate the pieces together and creates a more efficient process. This systems approach is combined with faculty course preferences, faculty time preferences, and student timeslot preferences to create an ideal schedule.

By applying operations research techniques and creating a couple transportation models along with an integrated decision support system, the time to create a schedule was drastically reduced. This system has was not just tested with data, but it has actually been used for IME department scheduling for the Fall 2010 term and will soon be used for the Winter 2011 term.

The resulting schedule achieved the goal of avoiding overlap of same level courses. This allows the students to keep on track with their graduation progress and potentially minimizes the delay caused by conflicts. The expected result of this should be a shorter time to graduation.

Since faculty input was solicited throughout the process, the response from the faculty members on the assignment and schedule generated was impressively positive with very few exceptions. Typically with the manual process approximately half the faculty members are not satisfied with the output and as a result there are often laborious changes that take place or faculty members have to compromise and must make special arrangements to accommodate the resulting schedule. 
When a faculty member has an assignment that fits their expertise and passion plus a schedule that fits their lifestyle, they are more likely to deliver high quality instruction. This approach supports the spirit of teaching and the enthusiasm that allows the higher education system to thrive.

All in all, this is a process improvement by creating a more efficient method that generates a higher quality outcome. This is Industrial Engineering at its best. 


\section{Bibliography}

Abdullah, Salwani, and Hamza Turabieh. "Generating University Course Timetable Using Genetic Algorithms and Local Search." Convergence and Hybrid Information Technology, 2008. . Busan , 2008. 254 - 260 .

$<$ http://www.ieexplore.ieee.org.ezproxy.lib.calpoly.edu:2048/stamp/stamp.jsp?tp $=\&$ arnumber $=4682035 \&$ isnumber $=4681984>$.

Abdullah, Salwani , Edmund Burke, and Barry McCollum. "A Hybrid Evolutionary Approach to the University Course Timetabling Problem." Proceedings of CEC. Singapore : IEEE Congress, 2007. 1764 - 1768 . $<$ http://www.ieeexplore.ieee.org.ezproxy.lib.calpoly.edu:2048/stamp/stamp.jsp?tp $=$ \&arnumber $=4424686 \&$ isnumber $=4424446>$.

Arous, Najet, Salah B. Abdallah, and Noureddine Ellouze. "Evolutionary Potential Timetables Optimization by Means of Genetic and Greedy Algorithms." Information Intelligence and Systems, 1999. Proceedings. Bethesda, MD : IEEE, 1999. $24-31$.

$<$ http://www.ieexplore.ieee.org.ezproxy.lib.calpoly.edu:2048/stamp/stamp.jsp?tp $=\&$ arnumber $=810220$ \&isnumber $=17541>$.

Badri, Masood A. et al. "A Multi-Objective Course Scheduling Model: Combining Faculty Preferences for Courses and Times ." Computers Ops Res 25.4 (1998): 303316.

Boronico, Jess. "Quantitative modeling and technology driven departmental course scheduling." Omega 28.3 (2000): 327-346 . 
Burke, E. K., and J. P. Newall. "A Multistage Evolutionary Algorithm for the Timetable Problem." IEEE Transactions on Evolutionary Computation. IEEE, 1999. <http://www.ieeexplore.ieee.org.ezproxy.lib.calpoly.edu:2048/stamp/stamp.jsp?tp $=\&$ arnumber $=752921 \&$ isnumber $=16264>$.

Carter, Michael, and Gilbert Laporte. "Recent developments in practical course timetabling." Practice and Theory of Automated Timetabling II. 1998. 3-19. <http://dx.doi.org/10.1007/BFb0055878>.

Fang, Sueychyun (Roger). “University Course Scheduling System (UCSS) - A UML Application with Database and Visual Programming." Journal of Computing Sciences in Colleges 20.6 (2005): 160-169.

Ghaemi, Sehraneh, Mohammad Taghi Vakili, and Ali Aghagolzadeh. "Using a Genetic Algorithm Optimizer Tool to Solve University Timetable Scheduling Problem." Signal Processing and Its Applications, 2007. ISSPA 2007. 9th International Symposium. Sharjah , 2007. 1 - 4. <http://www.ieeexplore.ieee.org.ezproxy.lib.calpoly.edu:2048/stamp/stamp.jsp?tp $=\&$ arnumber $=4555397 \&$ isnumber $=4555273>$.

Hertz, Alain, and Vincent Robert. "Constructing a course schedule by solving a series of assignment type problems." European Journal of Operational Research 108.3 (1998): 585-603.

Hinkin, Timothy, and Gary Thompson. "SchedulExpert: scheduling courses in the Cornell University School of Hotel Administration.." Interfaces 32.6 (2002): 45-57. 
Irene, Sheau Fen Ho, Safaai Deris, and Siti Zaiton Mohd Hashim. "A Combination of PSO and Local Search in University Course Timetabling Problem." Proceedings of the 2009 International Conference on Computer Engineering and Technology. IEEE Computer Society, 2009. 492-495. <http://www.ieeexplore.ieee.org.ezproxy.lib.calpoly.edu:2048/stamp/stamp.jsp?tp $=\&$ arnumber $=4769651$ \&isnumber $=4769538>$.

Kanoh, Hitoshi, and Yuusuke Sakamoto. "Interactive Timetabling System Using Knowledge-Based Genetic Algorithms." Systems, Man and Cybernetics, 2004 IEEE International Conference. 2004. 5852- 5857. <http://www.ieeexplore.ieee.org.ezproxy.lib.calpoly.edu:2048/stamp/stamp.jsp?tp $=\&$ arnumber $=1401129$ \&isnumber $=30425>$.

McClure, Richard H., and Charles E. Wells. "A Mathematical Programming Model for Faculty Course Assignments." Decision Sciences 15.3 (1984): 409-420.

Ojha, Prakash, and Abigail Walker. "A Comparison of Course Scheduling Methods." REU2000 2000. <http://www.cs.xu.edu/ lewandow/reu2000/paper/>.

"Orologio Class Timetabling System." Antinoos - Orologio - Class Timetabling Software. <http://www.antinoos.gr/en/orologio.htm>.

Parthiban, P et al. "Preferences Based Decision-making Model (PDM) for Faculty Course Assignment Problem." Engineering Management Conference, 2004. Proceedings. 2004 IEEE International . 2004. 1338 - 1341. <http://www.ieeexplore.ieee.org.ezproxy.lib.calpoly.edu:2048/stamp/stamp.jsp?ar number $=1408912 \&$ isnumber $=30511>$. 
Pesenti, Matthew . "Decision Support System for University Course Scheduling." 2002.

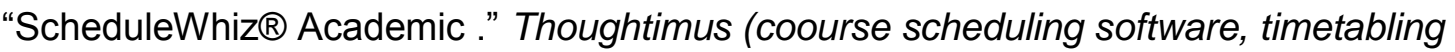
software). <http://www.thoughtimus.com/index_postsecondary.html>.

Thompson, Gary M. "Improving conferences through session scheduling." The Cornell Hotel and Restaurant Administration Quarterly 43.3 (2002): 71-76.

Thompson, Gary M. "Using information on unconstrained student demand to improve university course schedules." Journal of Operations Management 23.2 (2005): 197-208.

Wang, Yao-Te et al. "On the Application of Data Mining Technique and Genetic Algorithm to an Automatic Course Scheduling System." Cybernetics and Intelligent Systems, 2008 IEEE Conference. Chengdu, 2008. 400 - 405. $<$ http://ieeexplore.ieee.org.ezproxy.lib.calpoly.edu:2048/stamp/stamp.jsp?arnumb er $=4670852 \&$ isnumber $=4670728>$.

Wang, Yen-Zen. "An Application of Genetic Algorithm Methods for Teacher Assignment Problems." Expert Systems with Applications 22.4 (2002): 295-302.

Wang, Yen-Zen. "Using genetic algorithm methods to solve course scheduling problems." Expert Systems with Applications. 2003. 39-50. $<$ http://www.sciencedirect.com.ezproxy.lib.calpoly.edu:2048/science?_ob=Mlmg \&_imagekey=B6V03-47YXTVK-125\&_cdi $=5635 \&$ user=521828\&_orig=search\&_coverDate=07\%2F31\%2F2003\& 
sk=999749998\&view $=c \& w c h p=d G L b V t b-$

zSkzV\&md5=77f82fa754ee72af21e69739fefd0aba\&ie=/sdarticle.pdf>. 


\section{Appendix A: Examples of Manual Scheduling Templates}

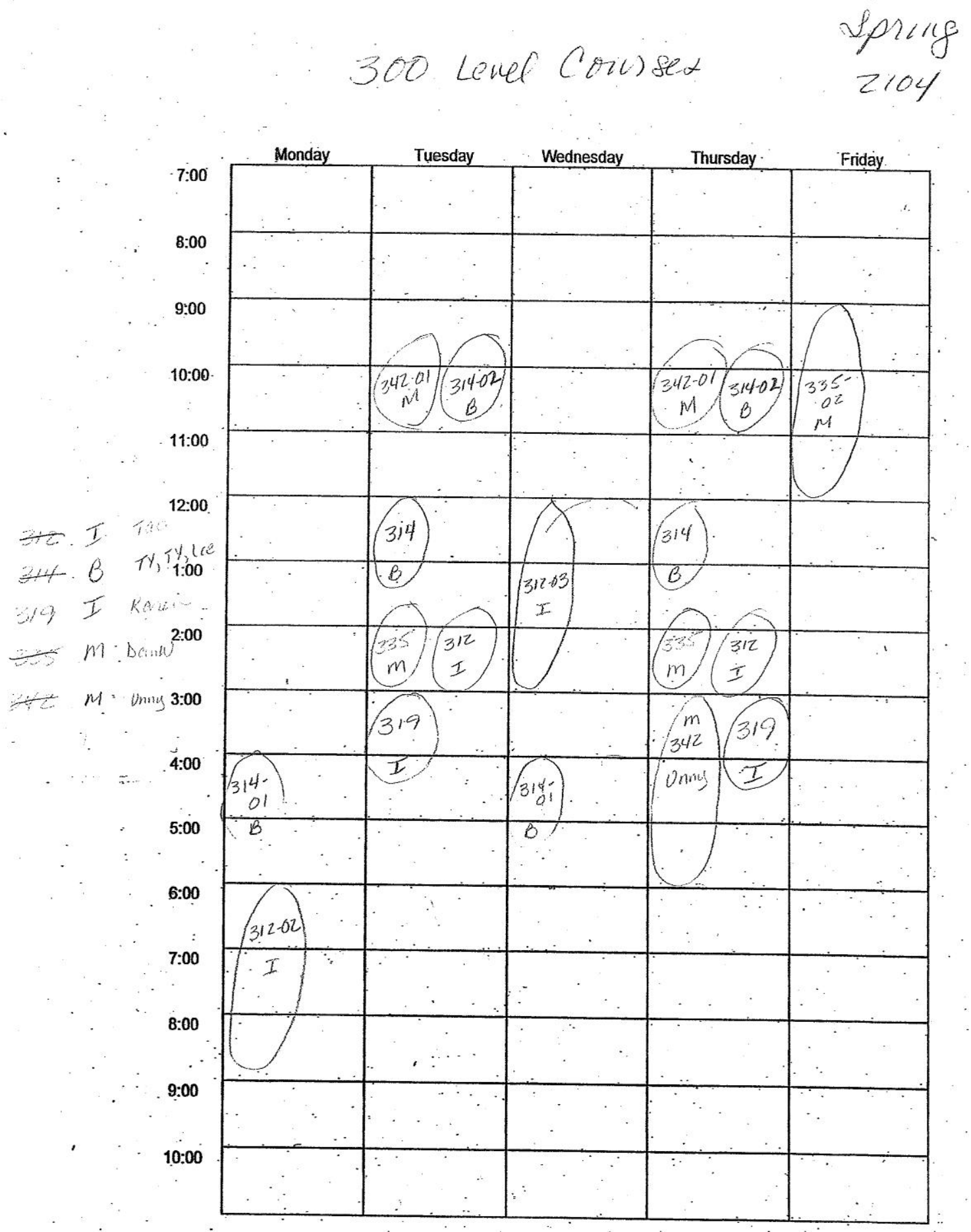

Figure 30: 300 Level Courses Manual Schedule Example 


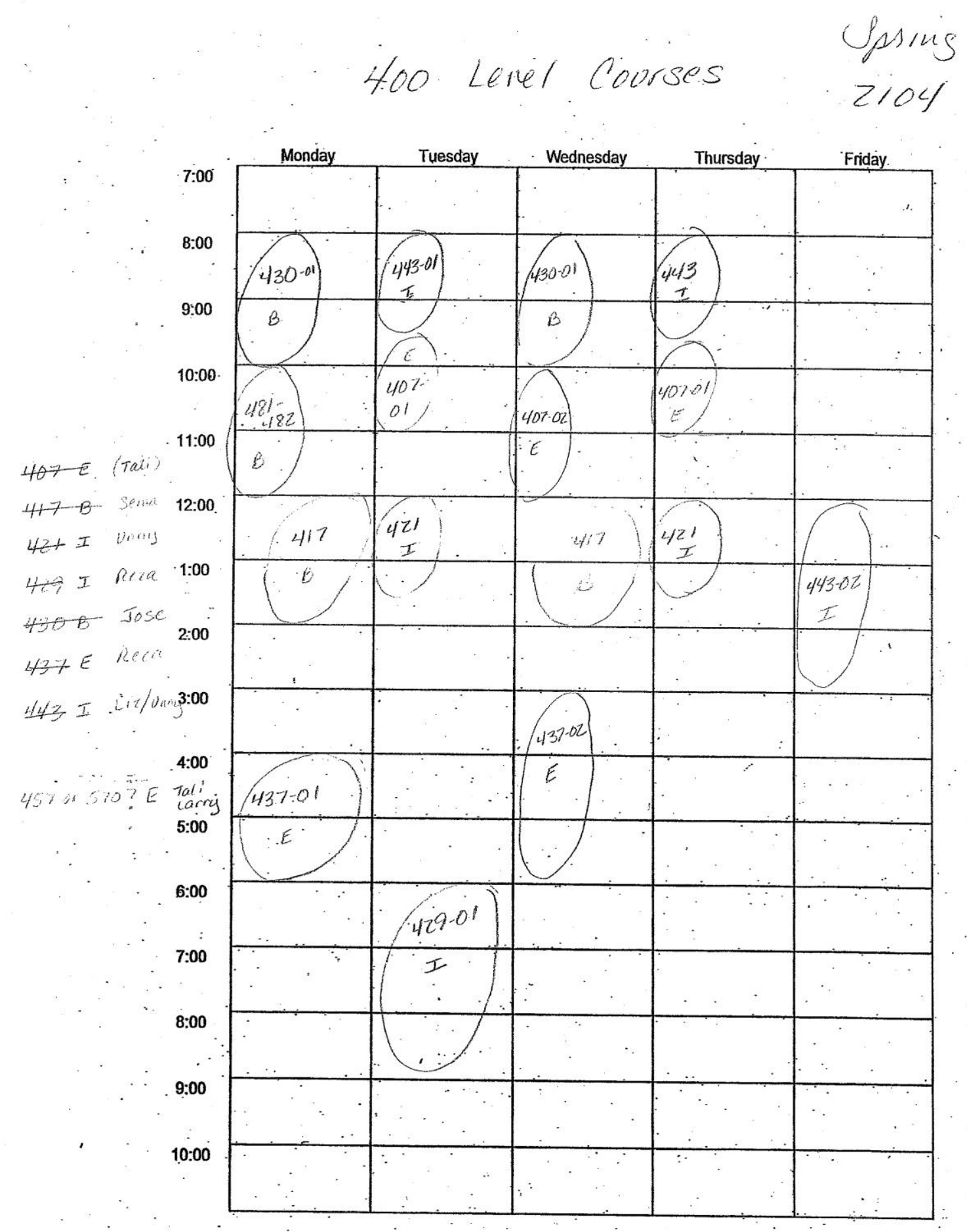

Figure 31: 400 Level Courses Manual Schedule Example 


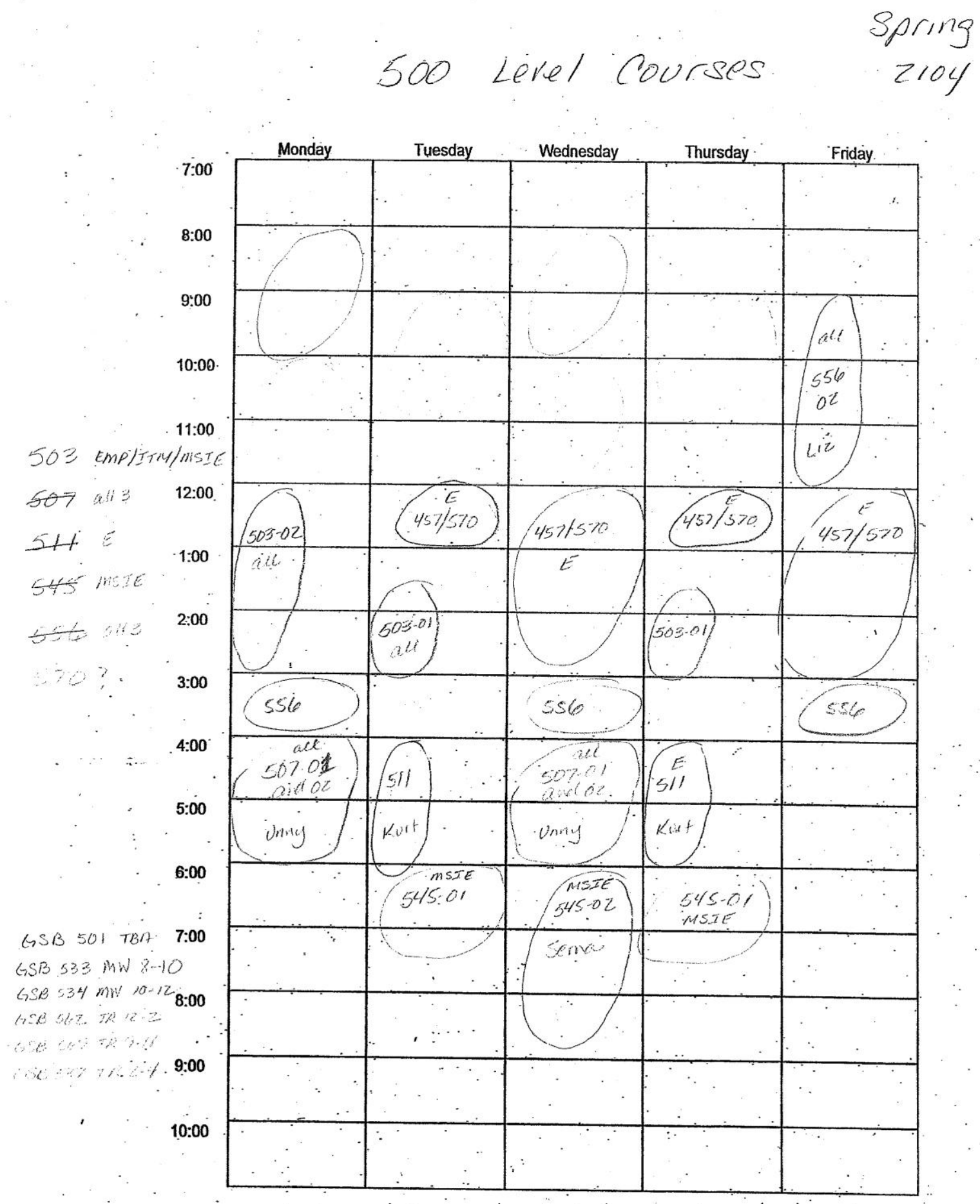

Figure 32: 500 Level Courses Manual Schedule Example 


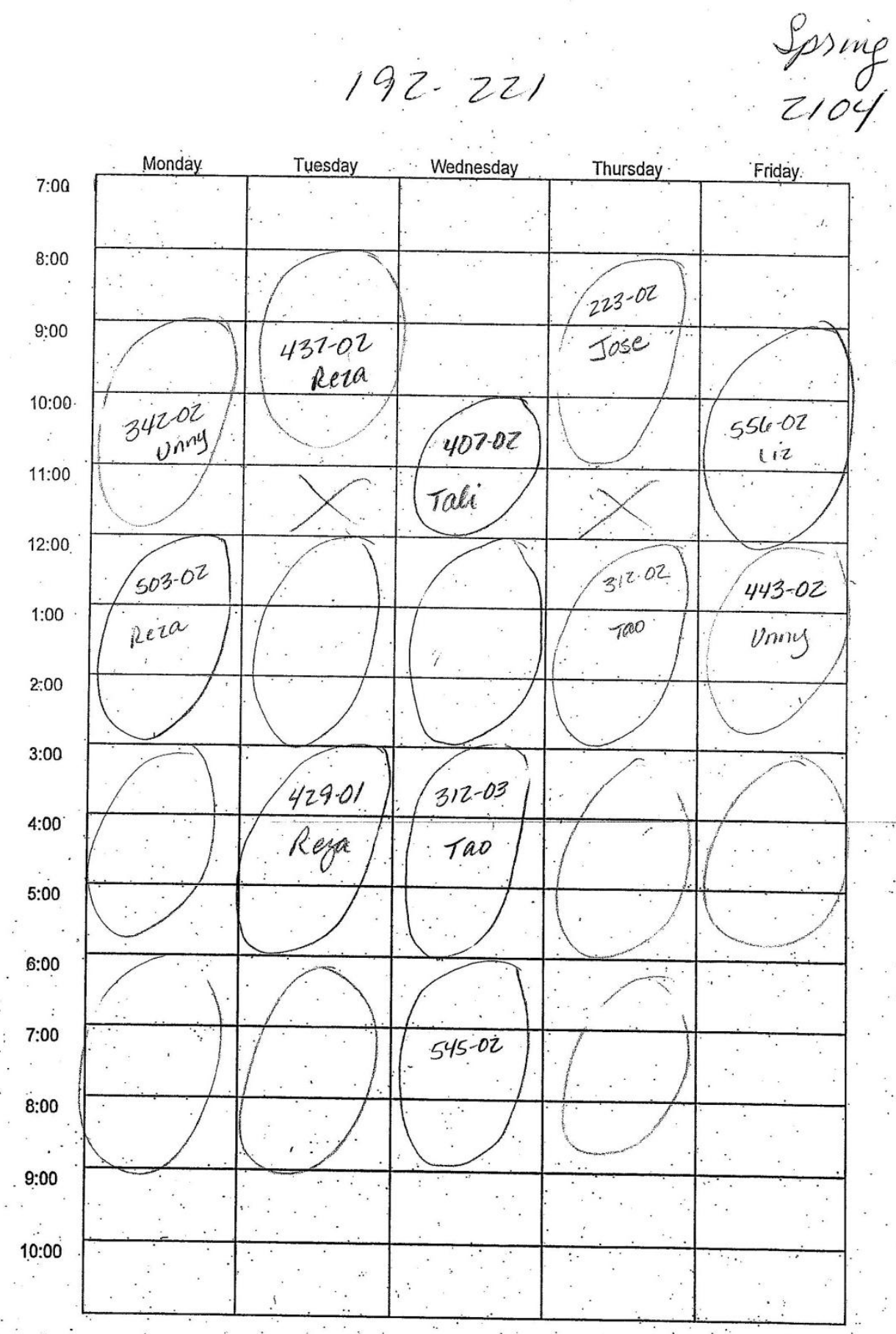

Figure 33: Lab Room 192-221 Manual Schedule Example 


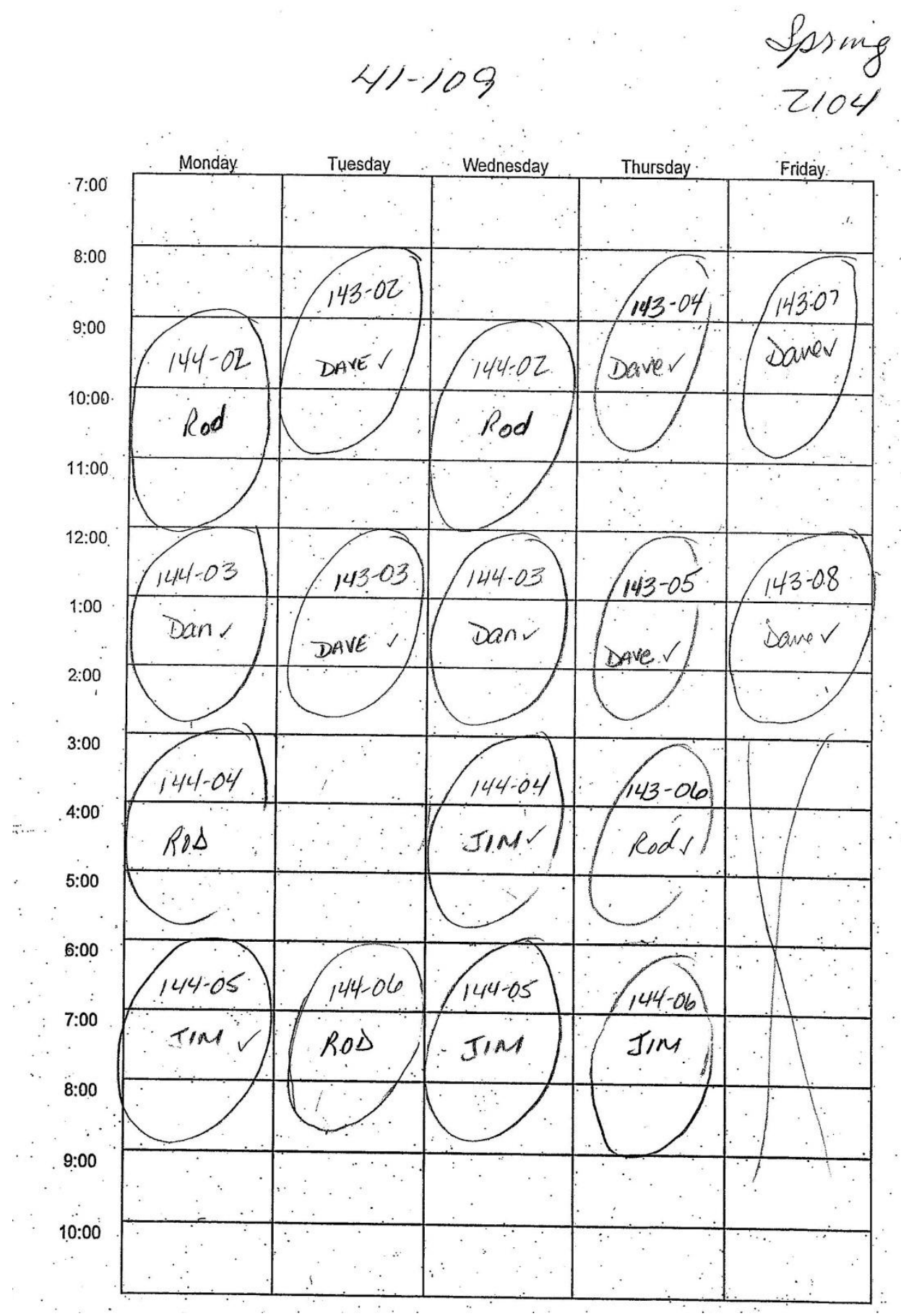

Figure 34: Lab Room 41-109 Manual Schedule Example 


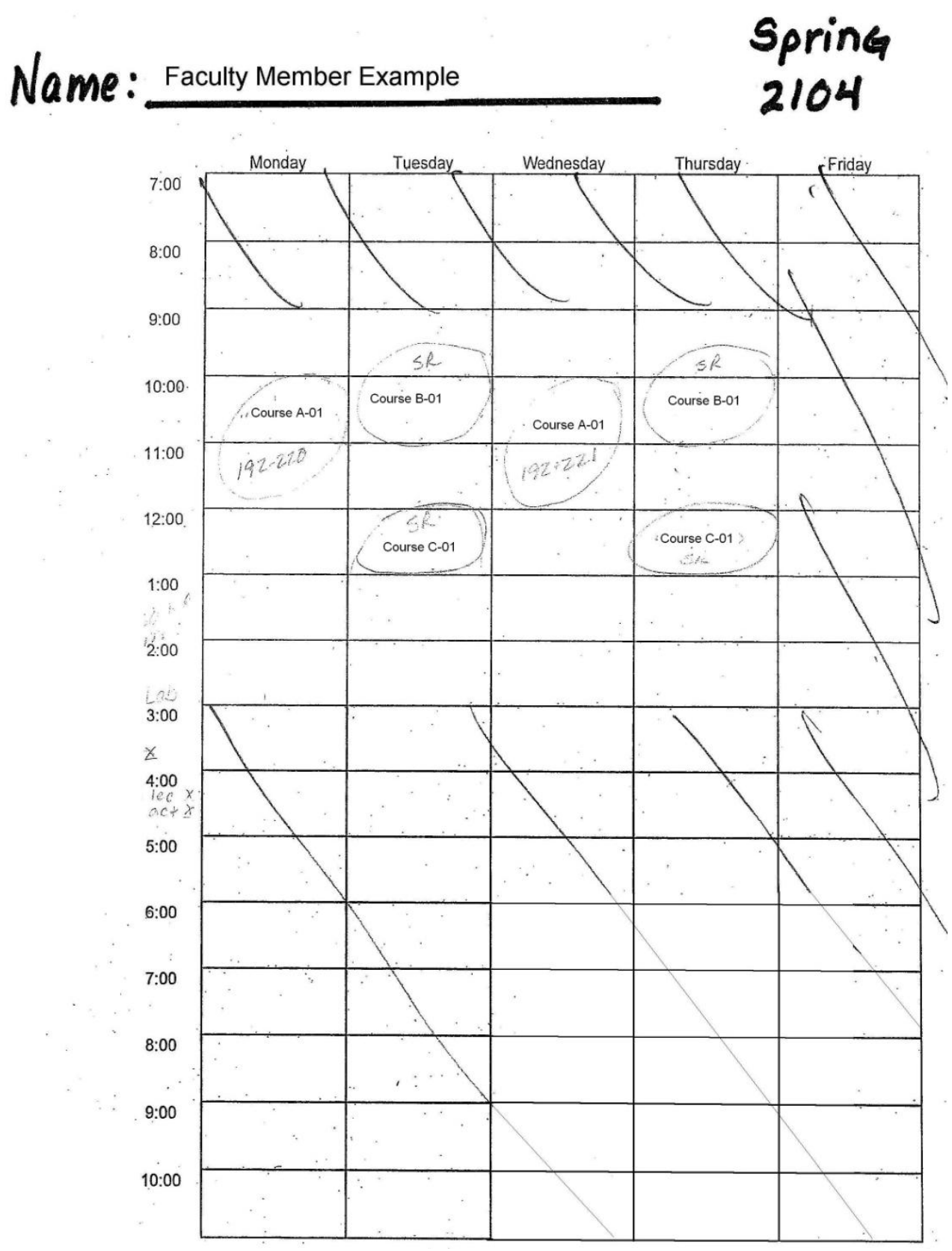

Figure 35: Faculty Member Manual Schedule Example 